\title{
AUTOMATED VEHICLES: A GUIDE FOR PLANNERS AND POLICYMAKERS
}

\author{
A Thesis \\ presented to \\ the Faculty of California Polytechnic State University, \\ San Luis Obispo
}

In Partial Fulfillment

of the Requirements for the Degree

Master of City and Regional Planning/Master of Science in Engineering

(Transportation Planning Specialization)

by

Charlie Coles

April 2016 
(C) 2016

Charlie Coles

ALL RIGHTS RESERVED 
COMMITTEE MEMBERSHIP

TITLE:

AUTHOR:

DATE SUBMITTED:

COMMITTEE CHAIR:

COMMITTEE MEMBER:

COMMITTEE MEMBER:
Automated Vehicles: A Guide for Planners and Policymakers

Charlie Coles

April 2016

William Riggs, Ph.D., AICP, LEED AP

Assistant Professor of City and Regional Planning

Michael Boswell, Ph.D., AICP

Professor of City and Regional Planning

Robert L. Bertini, Ph.D., P.E.

Associate Professor of Civil and Environmental Engineering 


\author{
ABSTRACT \\ Automated Vehicles: A Guide for Planners and Policymakers
}

\author{
Charlie Coles
}

\begin{abstract}
Automated vehicles are those which are capable of sensing their environments in order to perform at least some aspects of the safety-critical control (like steering, throttling, or braking) without direct human input. As a guide for planners and policymakers, the objective of this thesis is to develop a strong foundation for anticipating the potential impacts resulting from advancements in vehicle automation. To establish the foundation, this thesis uses a robust qualitative methodology, coupling a review of literature on the potential advantages and disadvantages of vehicle automation and lessons from past innovations in transportation, with recent trends of the Millennial Generation, carsharing services, and a series of interviews with thought-leaders in automation, planning, policymaking, transportation, and aviation. Five significant findings emerged from this thesis: (1) the impacts of vehicle automation differ depending on one's visions of what automation means, how it is implemented, what the automation does, and where it operates; (2) current limitations of vehicle automation to perform all aspects of the dynamic driving task in all driving conditions make it difficult to move from level4 to level-5 automation; (3) level-5 automation is required to have any effect on carsharing, mobility, and quality of life; (4) assuming effective planning and policymaking techniques, housing preferences, urban growth, and increases in total VMT will likely not be significantly impacted by vehicle automation; (5) human drivers may never be allowed to disengage their attention from a partially-automated vehicle, specifically in applications where drivers are expected to reengage their attention in safety-critical situations. From the perspective of understanding the bigger picture, this thesis developed a proposed future scenario of vehicle automation in the next five to ten years that is used to suggest guiding principles for policymakers, and key recommendations for planners, engineers, and researchers.
\end{abstract}

Keywords: Automated, Vehicles, Transportation, Planning, Policymaking, Millennials, Carsharing, Interviews, Aviation 


\section{ACKNOWLEDGMENTS}

I would like to thank my committee chair and members who helped to further develop the ideas of this thesis, and the interviewees for their incredible knowledge of automation, planning, transportation, policymaking, and aviation. I'm grateful to my father (Henry Coles), my mother (Laurie Coles), and my brother (Andy Coles) for their support while I completed my Master's degrees. I would like to especially thank my soon to be wife, Yagmur llgen, whose inspiration, encouragement, and love made this all possible. 


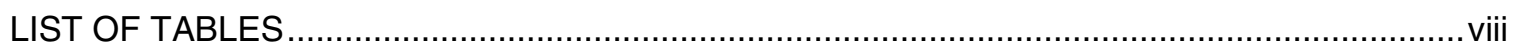

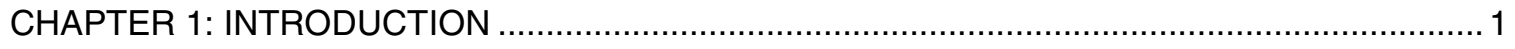

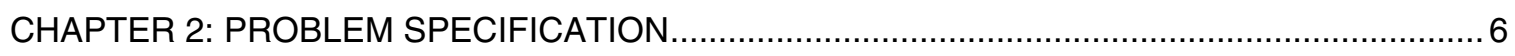

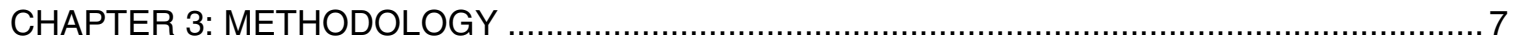

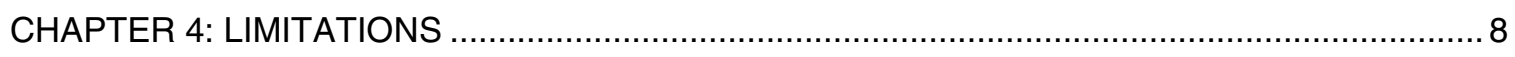

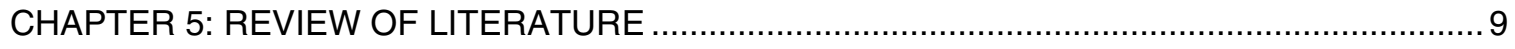

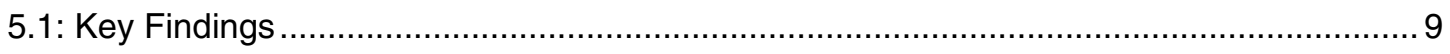

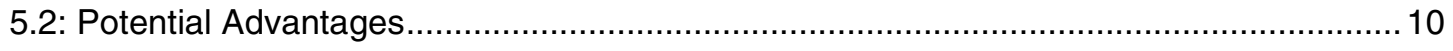

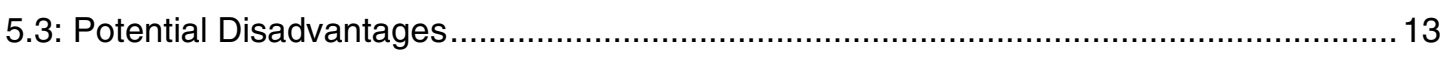

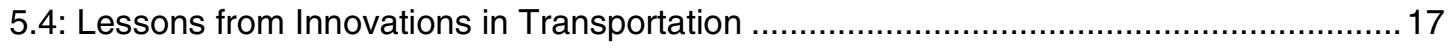

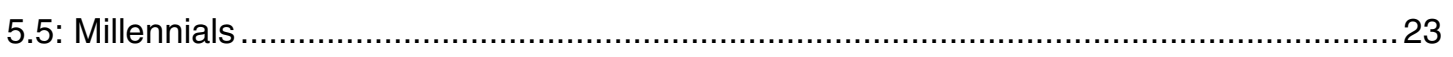

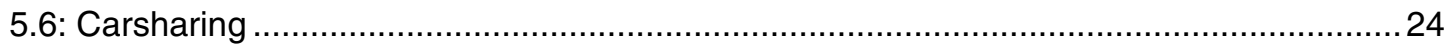

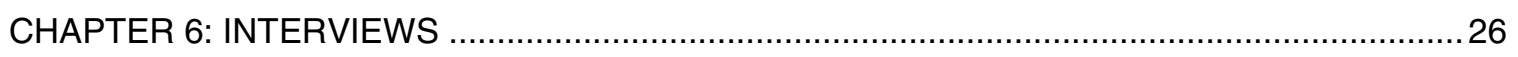

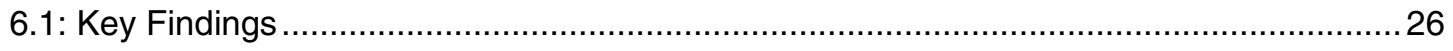

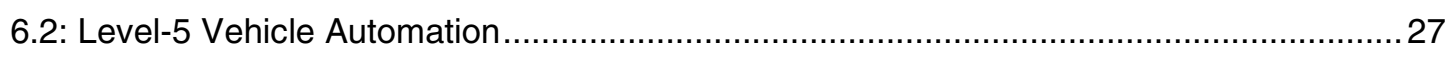

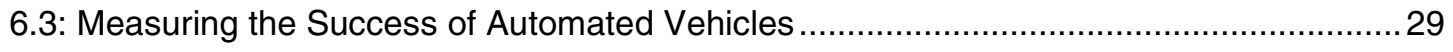

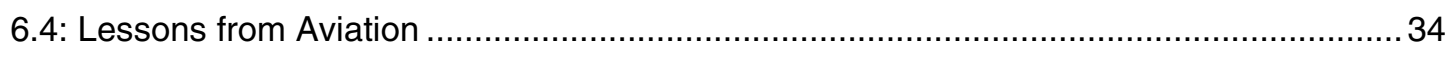

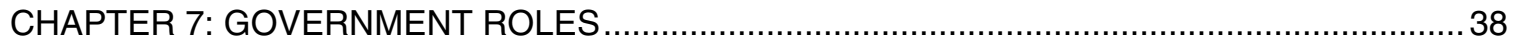

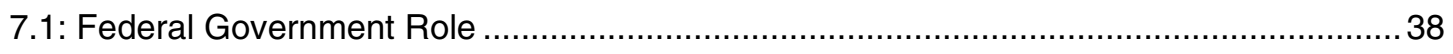

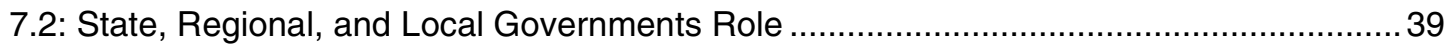




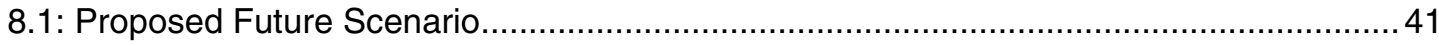

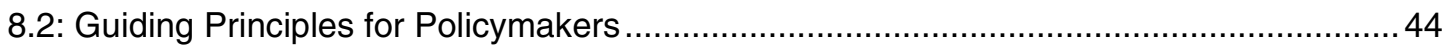

8.3: Conclusions for Planners, Engineers, and Researchers........................................... 47

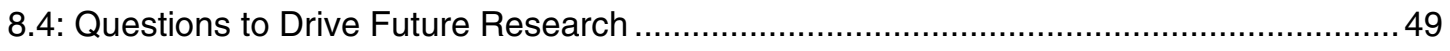

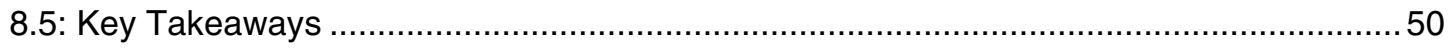

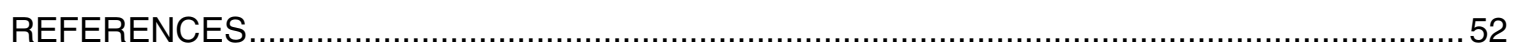

APPENDICES

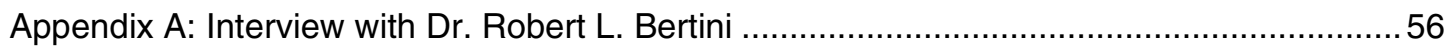

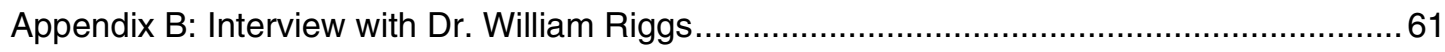

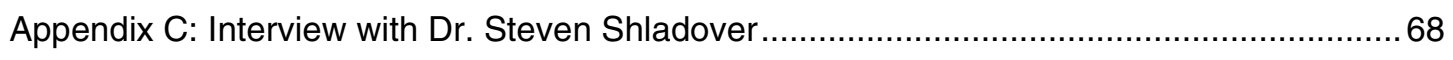

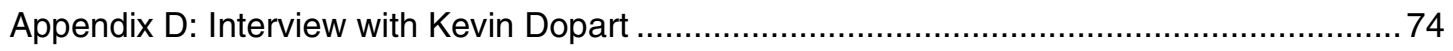

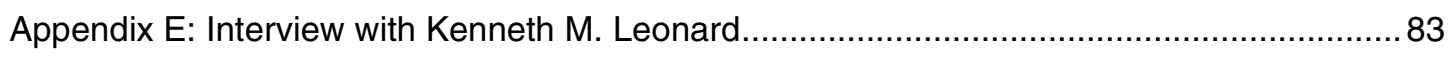

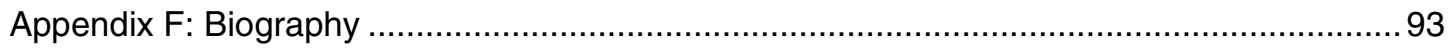




\section{LIST OF TABLES}

Table

Page

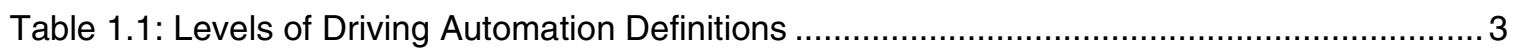

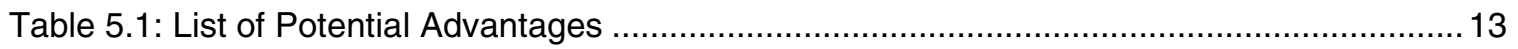

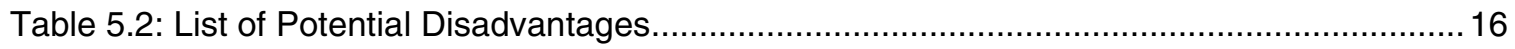

Table 5.3: Comparison of Potential Advantages and Potential Disadvantages .......................... 17

Table 5.4: Lessons from Innovations in Transportation Matrix .................................................... 19 


\section{CHAPTER 1: INTRODUCTION}

At the 1939 World's Fair, Norman Bel Geddes's Futurama exhibit portrayed radiocontrolled electric cars propelled by electromagnetic fields through circuits embedded in the roadway. Later, Bel Geddes outlined his vision in his book, Magic Motorways (1940), detailing developments in highway design and transportation, predicting a revolutionary development in the Interstate Highway System, and arguing that humans should be removed from the driving process. Now, more than 75 years later, the developments in automated vehicle technology position us on the brink of another revolution in transportation. As railways transformed the way we travelled in the $19^{\text {th }}$ century, and the motor car in the $20^{\text {th }}$ century, the automated vehicle will modernize transport in the $21^{\text {st }}$ century (Le Vine et al., 2014).

Automated vehicles, also termed autonomous, driverless, self-driving and robotic vehicles, are vehicles capable of sensing their environments and navigating without human input, thus fulfilling the capabilities of a traditional vehicle. The Society of Automotive Engineers' (SAE) International On-Road Automated Vehicle Standards Committee (2014) has established the definitions of increasing levels of vehicle automation that are used throughout this thesis. The increasing levels in automated technology are most easily conceptualized using the six definitions provided in Table 1.1. This hierarchy and respective definitions are also summarized here:

- No Automation (Level 0): The full-time performance by the human driver of all aspects of the dynamic driving task, even when enhanced by warning or intervention systems. At this level, the driver is in complete and sole control at all times.

- Driver Assistance (Level 1): The driving mode-specific execution by a driver assistance system of either steering or acceleration/deceleration using information about the driving environment and with the expectation that the human driver perform all remaining aspects of the dynamic driving task. At this level, the driver carries out all lane holding or lane changes but vehicles are equipped with technology to control one or more specific functions. Examples of this level includes: stability control and pre-charged brakes. 
- Partial Automation (Level 2): The driving mode-specific execution by one or more driver assistance systems of both steering and acceleration/deceleration using information about the driving environment and with the expectation that the human driver perform all remaining aspects of the dynamic driving task. At this level, the system handles lane holding and lane changes in special applications. The driver must continuously monitor the system. Examples of this level includes: adaptive cruise control and autopilot capabilities along certain roadways and locations.

- Conditional Automation (Level 3): The driving mode-specific performance by an automated driving system of all aspects of the dynamic driving task with the expectation that the human driver will respond appropriately to a request to intervene. At this level, the driver no longer needs to continuously monitor the system but must be available to take over when needed. An example of this level would show a system performing lane holding and changing in specific cases; the system detects limits and asks the driver to take over with sufficient warning.

- High Automation (Level 4): The driving mode-specific performance by an automated driving system of all aspects of the dynamic driving task, even if a human driver does not respond appropriately to a request to intervene. At this level, vehicles do not require a driver in special applications; automated systems can handle all situations in the specific application case. An example of this level would show an automated vehicle operating in a specific or controlled environment.

- Full Automation (Level 5): The full-time performance by an automated driving system of all aspects of the dynamic driving task under all roadway and environmental conditions that can be managed by a human driver. At this level, the driver is not expected to take control of the vehicle at any time. The vehicle is capable of performing all safety-critical driving functions and can monitor roadway conditions for an entire trip; this includes both occupied and unoccupied vehicles. 
Table 1.1: Levels of Driving Automation Definitions

\begin{tabular}{|c|c|c|c|c|c|c|}
\hline $\begin{array}{l}\Gamma \\
\mathbb{\Phi} \\
\Phi \\
\Phi\end{array}$ & Name & Definition & $\begin{array}{l}\text { Execution of } \\
\text { steering and } \\
\text { acceleration/ } \\
\text { deceleration }\end{array}$ & $\begin{array}{l}\text { Monitoring } \\
\text { of driving } \\
\text { environment }\end{array}$ & $\begin{array}{l}\text { Fallback } \\
\text { performance } \\
\text { of dynamic } \\
\text { driving task }\end{array}$ & $\begin{array}{l}\text { System } \\
\text { capability } \\
\text { (driving } \\
\text { modes) }\end{array}$ \\
\hline \multicolumn{7}{|c|}{ Human driver monitors the driving environment } \\
\hline 0 & $\begin{array}{l}\text { No } \\
\text { Automation }\end{array}$ & $\begin{array}{l}\text { The full-time performance by the human driver of all } \\
\text { aspects of the dynamic driving task, even when } \\
\text { enhanced by warning or intervention systems }\end{array}$ & Human driver & Human driver & Human driver & $\mathrm{N} / \mathrm{A}$ \\
\hline 1 & $\begin{array}{l}\text { Driver } \\
\text { Assistance }\end{array}$ & $\begin{array}{l}\text { The driving mode-specific execution by a driver } \\
\text { assistance system of either steering or } \\
\text { acceleration/deceleration using information about } \\
\text { the driving environment and with the expectation } \\
\text { that the human driver perform all remaining aspects } \\
\text { of the dynamic driving task }\end{array}$ & $\begin{array}{l}\text { Human driver } \\
\text { and system }\end{array}$ & Human driver & Human driver & $\begin{array}{l}\text { Some driving } \\
\text { modes }\end{array}$ \\
\hline 2 & $\begin{array}{l}\text { Partial } \\
\text { Automation }\end{array}$ & $\begin{array}{l}\text { The driving mode-specific execution by one or more } \\
\text { driver assistance systems of both steering and } \\
\text { acceleration/deceleration using information about } \\
\text { the driving environment and with the expectation } \\
\text { that the human driver perform all remaining aspects } \\
\text { of the dynamic driving task }\end{array}$ & System & Human driver & Human driver & $\begin{array}{l}\text { Some driving } \\
\text { modes }\end{array}$ \\
\hline \multicolumn{7}{|c|}{ Automated driving ("system") monitors the driving environment } \\
\hline 3 & $\begin{array}{l}\text { Conditional } \\
\text { Automation }\end{array}$ & $\begin{array}{l}\text { The driving mode-specific performance by an } \\
\text { automated driving system of all aspects of the } \\
\text { dynamic driving task with the expectation that the } \\
\text { human driver will respond appropriately to a request } \\
\text { to intervene }\end{array}$ & System & System & Human driver & $\begin{array}{l}\text { Some driving } \\
\text { modes }\end{array}$ \\
\hline 4 & $\begin{array}{l}\text { High } \\
\text { Automation }\end{array}$ & $\begin{array}{l}\text { The driving mode-specific performance by an } \\
\text { automated driving system of all aspects of the } \\
\text { dynamic driving task, even if a human driver does } \\
\text { not respond appropriately to a request to intervene }\end{array}$ & System & System & System & $\begin{array}{l}\text { Some driving } \\
\text { modes }\end{array}$ \\
\hline 5 & $\begin{array}{l}\text { Full } \\
\text { Automation }\end{array}$ & $\begin{array}{l}\text { The full-time performance by an automated driving } \\
\text { system of all aspects of the dynamic driving task } \\
\text { under all roadway and environmental conditions that } \\
\text { can be managed by a human driver }\end{array}$ & System & System & System & $\begin{array}{l}\text { All driving } \\
\text { modes }\end{array}$ \\
\hline
\end{tabular}

Source: SAE International (2014) 
There is fierce competition between established car companies, like Mercedes Benz, General Motors, Nissan and many others, and newer technology companies, such as Google, Uber and Tesla, to advance the field of vehicle automation (Davidson et al., 2015). The internet giant, Google, has become widely acknowledged as the world leader in fully-automated vehicle research since October 2010, when they first announced they had entered the field and had already logged over 100,000 miles (Waldrop, 2015). As of late, Google has logged more than one million miles of testing in their fleet of fully-automated vehicles on the streets near their headquarters in Mountain View, California, as well as in Austin, Texas and Kirkland, Washington (Google, 2016). Tesla predicts that fully automated vehicles-what Elon Musk defines as "true autonomous driving where you could literally get in the car, go to sleep and wake up and your destination"-will be available to the public by 2020 (Mack, 2014). There are still many aspects of vehicle automation that need refining, including legal, liable, technical, and social problems; however, one thing is certain, vehicle automation has the potential to revolutionize the way humans interface with the transportation system (Fagnant et al., 2015).

The buzz around automated vehicle technology has sparked an industry dedicated to the development of special-purpose, low-speed automated vehicles in the form of robotic shuttles (Kirk, 2016). Companies around the world, like DeNA, Navya, LUTZ, and EasyMile, are bridging the gap between vehicle manufacturers and high tech company specialists in robotics to develop driverless shuttle systems. Organizations, such as CityMobil2, are developing pilot programs for automated road transport systems in several urban environments (Shladover et al. 2015). In addition, this seemingly rapidly developing technology has ignited research into almost every aspect of society, like the technical, financial, cultural, legal, economic, environmental, and behavioral effects on land use policies, and how new systems will be integrated into existing infrastructure (U.S. DOT, 2015).

The bulk of this thesis is organized into a review of literature, which brings together relevant information on the potential advantages and disadvantages of vehicle automation and lessons from past innovations in transportation, with recent trends of the Millennial Generation, 
and carsharing services. In an effort to contribute meaningful information back to the planning professions, this thesis pursued the robust review of literature using a variety of sources as a framework to help industry professionals better understand and anticipate the effects of automated vehicles.

The information gathered in the review of literature provided the background data necessary to develop interview questions that were asked to experts of vehicle automation, urban and transportation planning, policy, aviation, and related areas. Interviews make up the second major component of this thesis and are organized based on the similar topics discussed: level-5 automation, measuring the success of automated vehicles, and lessons from aviation. To bring the information together, this thesis provides an in depth discussion, which joins the data gathered during the review of literature with that which was revealed during the interviews. From the perspective of understanding the bigger picture, this thesis developed a proposed future scenario of vehicle automation in the next five to ten years that is used to suggest guiding principles for policymakers, and key recommendations for planners, engineers, and researchers. By understanding the key lessons discussed in this thesis, planners and policymakers will receive more clarity in order to critically evaluate the anticipated effects of automated vehicles. This thesis should be utilized as an educational tool, allowing industry professionals and the public at large to begin thinking about how automated vehicles have the potential to influence change within society. 


\section{CHAPTER 2: PROBLEM SPECIFICATION}

The automobile was perhaps the most influential invention in transportation of the 20th century and even today, the personal automobile is used by most as their primary mode of transportation (Meyer, 2016). As of 2015 , there are presently over 800 million cars on the road worldwide, and more than $75 \%$ of Americans commute alone by car (U.S. Census, 2009-2013). The average family organizes car-related expenses as their second highest expense below rent, mortgage, or home expenses (U.S. DOT, 2015). Americans typically spend an average of 100 hours a year in traffic (Cowen, 2011), with around 33,000 people killed annually in the nearly 5.7 million highway traffic accidents in the United State alone. Traffic congestion accounts for 3.7 billion wasted hours and 2.3 billion wasted gallons of fuel. Additionally, cars utilize less than $4 \%$ of their lifetime wasting precious natural resources and space when not in use because of our nation's strong emphasis on personal car ownership (Thrun, 2010). Despite the significance automobiles have on daily life, there has been a considerable lack of automotive innovation in the past decade; however, this lack in innovation will soon change as fleets of automated vehicles are deployed into society.

Planning and policymaking is a future oriented activity that is concerned with the use of land, protection of the environment and public welfare, and is capable of confronting inconceivable problems (Patton et al., 2015); however, these professions currently face their own problem by being left without a reasonable range of outcomes regarding higher levels of vehicle automation (Davidson et al., 2015). In addition, there are many potential applications and differing timelines of how and where automated vehicles will be released that present numerous unknowns and assumptions contributing to the complexity of this problem. Without a fundamental understanding of how, where, and when higher levels of vehicle automation will be implemented, planners and policymakers will have a difficult time anticipating changes and, as a result, making decisions and providing recommendations for the future. 


\section{CHAPTER 3: METHODOLOGY}

The methodology used in this thesis was developed using recommendations from Patton's (2015) Basic Methods of Policy Analysis and Planning. This thesis uses a qualitative research methodology that combines a thick description of automated vehicles, a robust literature survey, information on recent generational trends and share-based transportation services gathered from trustworthy documents, as well as speculative resources, into a review of literature, which organizes and discusses the relevant findings from independent studies. The information from the review of literature provides the background, context, and basic facts necessary to develop and complete a series of interviews with experts in vehicle automation, urban and transportation planning, research, policy, aviation, and related fields. The series of interview questions in this thesis are aimed toward learning more about vehicle automation, discovering new lessons which may be underrepresented from experts in relevant industries, uncovering other analogous examples from past innovations in transportation, and receiving feedback to solidify the foundation and approach developed in this research methodology. In addition, the varying sources of information from literature and findings from the interviews are compared and validated against each other in order to strengthen the arguments made in this thesis. 


\section{CHAPTER 4: LIMITATIONS}

Currently, higher levels of vehicle automation are not widely adopted, making it difficult to predict how the technology will unfold. Vehicle automation may take on an entirely different form than what is currently familiar to the public. In addition, as more information becomes available to the profession, people's stated preferences and overall thoughts for vehicle automation may change.

While many efforts were made to ensure impartial data collection, there was still bias in resource selection, which primarily focused around topics directly relevant to transportation and planning, and pertinent policymaking. There are also a wide range of variables that could be considered when estimating the effects of automated vehicles; as a result, it is likely not all variables will be discussed. The abundance of information on automated vehicles released throughout the development of this thesis made it challenging to stay up to date with the most recent research. It should also be noted that some of the information presented in peer-reviewed publications are based on speculation. This thesis cross-references data against other peerreviewed resources in order to strengthen the validity of the arguments made.

This thesis was constrained by time and resources. Interviews only lasted for approximately one hour, allowing for a finite amount of time for questions and answers. More time, as well as more experience with the interview process, would improve the quality of results. A larger number of interviews with thought-leaders would strengthen this type of research in the future. In addition to the thought-leaders interviewed in this thesis, experts in other relevant fields, such as in computer technology, law, environment, psychology, business, ethics and more, would also strengthen future research. 


\section{CHAPTER 5: REVIEW OF LITERATURE}

This thesis begins with a review of existing literature on vehicle automation topics that are perceived to be relevant to urban and transportation planning, and policymaking. The thesis identifies studies joining automated vehicles to potential effects on society and cities by means of Google and Google Scholar databases using the keywords "automated," "driverless,"

"autonomous," "robotic," "vehicle," "car," "automobile," "benefit," "problem," "advantage," "disadvantage," “innovation,” "transportation," "society," "monocentric city model," "carsharing," "Generation Y," "Millennials," "policy," and "regulation." Additionally, a review of the Transportation Research Board's TRID database and proceedings from the latest Automated Vehicles Symposium was conducted to identify relevant research. This thesis examines references of previous literature reviews in similar subject areas in order to identify other relevant studies. It should be noted that new information had been released during the development of this thesis and may not be included due to time constraints. This information provided the background and context, basic facts, political attitudes and resources or major players, ideas about the future, and additional contacts and materials necessary to fulfill the methodology.

\section{1: Key Findings}

- The impacts of vehicle automation on roadway congestion, automobile dominance, and VMT cannot be accurately predicted at this time.

- Vehicle automation technology may first become available to more-affluent households who can afford to pay the higher costs of travel.

- Millennials are multimodal, interested in share-based transportation services, attracted to leveraged technology for transit, and choose how they get around based on their budget and lifestyle.

- Level-5 automation has the potential to enable a new model of urban mobility by facilitating carsharing, a share-based transportation service shown to reduce car use and VMT. 


\section{2: Potential Advantages}

One of the popular advantages of vehicle automation is the potential to improve roadway safety (Bierstedt et al., 2014; Anderson et al., 2014). According to the National Highway Traffic Safety Administration (NHTSA) (2008), driver error is believed to account for over $90 \%$ of all crashes. In addition, approximately $31 \%$ of all motor vehicle traffic fatalities are attributed to alcohol impairment. Automated vehicles are expected to be programmed to obey traffic laws, like roadway speeds, and will likely have faster reaction times compared to human drivers (Fagnant,

at al., 2014; Flämig et al., 2015; Hendrickson et al., 2014). The safety benefits of this technology would not necessarily require higher levels of vehicle automation since these same safety benefits could be realized through the form of a vehicle intervention system. This advantage could influence vehicle designs as they would no longer require heavy safety features, like reinforced steel frames, crumple zones, and airbags, as well as roadside designs, such as guard rails and crash cushions (Somers et al., 2015; Fraedrich et al., 2014; Silberg et al., 2012).

Automated vehicle technology has the potential to improve fuel efficiency and reduce greenhouse gas emissions in at least three primary ways: more efficient driving; lighter, more fuel-efficient vehicles; efficient infrastructure (Silberg et al., 2012; Folsom, 2011; Guerra, 2014; Howard et al., 2014). The inefficiency currently observed by human vehicle operation is projected to improve with a fully automated vehicle roadway network. Automated vehicles and their ability to platoon would reduce the drag coefficient, thus reducing highway fuel use by up to 20 percent (Silberg, 2012). In addition, automated vehicles have the potential to improve the roadway network's efficiency, thus reducing $\mathrm{CO}_{2}$ emissions and other particulate matter released into the atmosphere (U.S. DOT, 2015; Fagnant et al., 2014). Automated vehicles would also be able to communicate information with each other and with smart infrastructure, thus allowing for the opportunity that these vehicles could inform other vehicles about upcoming traffic conditions (Furda et al., 2010). These advantages, among others, could be realized through vehicle connectivity and improved through higher levels of vehicle automation (Anderson et al., 2014). As 
vehicles become more informed on upcoming roadway conditions, more intelligent software could be developed in order to minimize energy use based on said information.

Automated vehicles have the potential to improve travelers' productivity by allowing for other activities to occur while traveling (Cyganski et al., 2015; Somers et al., 2015; U.S. DOT, 2015; Silberg et al., 2012; Billings, 1996; Hendrickson et al., 2014). Being able to work, study, or sleep while traveling could improve the quality of life for individuals using the technology. This advantage would require the highest levels of vehicle automation, level- 4 or -5 , where the vehicle is capable of completing all, or nearly all, of the required driving tasks (Bierstedt et al., 2014). Increased driving time has been strongly correlated to increased stress levels in commuters; professor and director of the New England Transportation Center, Joseph Coughlin, stated that, "stress is a safety issue, and it is a quality-of-life issue (Dizikes, 2010)." Reducing the stress of driving, by completely eliminating the need to focus on maneuvering the vehicle, would potentially allow motorists to rest and/or even work while traveling (Flämig et al., 2015; Anderson et al., 2014; Shaheen et al., 2006; Cyganski et al., 2015; Billings, 1996).

Level-5 vehicle automation has the ability to provide independent mobility for non-drivers, thus reducing the need for motorists to chauffeur non-drivers, and to subsidize public transit (U.S. DOT, 2015). As age increases, visual acuity, flexibility, strength, reaction time, and memory all decline and impact a person's ability to drive a vehicle (Guerra, 2014; Fagnant, at al., 2014; Somers et al., 2015; Cheon, 2003; Flämig et al., 2015; Anderson et al., 2014). Some elderly drivers voluntarily give up their privilege to drive, yet many others do not, resulting in an increased risk to themselves and others. Losing the privilege to drive can lead to a serious reduction in social interaction with friends and family, and an inability to shop and access health care services, thus reducing one's quality of life and health (Lutin et al., 2013). Additionally, fully-automated vehicles have the potential to provide younger generations with a form of mobility (Silberg et al., 2012; Bierstedt, at al., 2014). While some of these individuals over the age of 15 years old will have licenses and access to a private vehicle, or access to other modes of transportation, others may also rely on friends or family members for transportation. Fully-automated vehicles have the 
potential to offer older residents, children, and persons with disabilities with a reliable mode of travel, especially those living in suburban or rural areas where public or alternative methods of transportation may not be available or possible (Anderson et al., 2014).

Fully-automated vehicles would also likely be used in the movement of goods and care giving services (Le Vine et al., 2014; Somers et al., 2015). The ability to transport goods and passengers without a driver would significantly reduce labor costs. The effects automated vehicles would have on productivity and society at large is limited only by one's imagination as the technology is implemented and develops (Lutin et al., 2013). In addition, fully-automated vehicles have the potential to reduce costs for individual users and households by eliminating the need of paid drivers for taxis and commercial transport, and accommodating carsharing services (Silberg et al., 2012). If automated vehicles support carsharing services, then each vehicle would have the potential to serve more people, thus reducing demand for parking infrastructure and improving roadway capacity (Dutzik et al., 2013; Silberg et al., 2012; Flämig et al., 2015; Anderson et al., 2014).

Automated vehicles have the potential to save on costs associated with parking, roadway improvements, and roadway expansions to accommodate for increased demand (Guerra, 2014; Fagnant et al., 2014; Howard et al., 2014; Cyganski et al., 2015; Somers, at al., 2015; Fraedrich et al., 2014; U.S. DOT, 2015; Bierstedt et al. 2014; Flämig et al., 2015). Research suggests automated vehicles may improve roadway capacity without building additional lanes or roadways (Silberg et al., 2012); however, potential bottlenecks at ramps, intersections, and other cases will likely limit how much roadway capacity can be improved (Guerra, 2014; Cheon, 2003; U.S. DOT, 2015). Automated vehicles could have the ability to platoon, the act of electronically linking vehicles to a lead vehicle in the formation of a "road train," thus creating a potential for increasing roadway capacity by allowing narrower lanes, and reduced intersection stops, reduced congestion and roadway costs (Lutin et al., 2013; Le Vine et al., 2014; Folsom, 2011; Fagnant et al., 2014; Howard et al., 2014; Somers et al., 2015; Silberg et al., 2012; Flämig et al., 2015; Anderson et al., 2014). Today's roadways are designed to accommodate for imprecise and 
unpredictable human driving behaviors. Infrastructure like extra-wide lanes, guardrails, stop signs, wide shoulders, and rumble strips may not be required once automated vehicles have been fully adopted. More efficient parking strategies could also be developed, like software designed to efficiently locate open parking spaces, or parking locations could change all together.

Table 5.1 provides a list of the potential advantages associated with vehicle automation identified in existing literature. Sources provided below the table use superscripts to connect the source to the respective topic being discussed.

\section{Table 5.1: List of Potential Advantages}

Improved safety and public health 1, 2, 6, 9, 10, 12, 13, 15, 20, 21

Better productivity and quality of life $1,3,5,6,7,10,15,18,19,20,21$

Reduced energy and environmental impact 1,7, 9, 11, 14, 16, 20

Less congestion ${ }^{11,13,14,16,20}$

Saved costs associated with roadway improvements and expansions 1, 9, 10, 11, 14, 16, 17, 18, 20, 21

Decreased total cost, or proportion of income, spent on transportation 1, 2, 5, 7, 9, 10, 12, 14, 16, 20, 21

Accommodated carsharing services ${ }^{1,8,10,17,18,19,20,21}$

Increased mobility, accessibility and travel options 1, 2, 4, 7, 9, 10, 14, 18, 20, 21

Sources: Anderson et al. (2014) ${ }^{1}$; Bierstedt et al. (2014) ${ }^{2}$; Billings (1996) Cyganski et al. (2015) $(2014)^{9}$; Flämig et al. (2015) ${ }^{10}$; Folsom (2011) ${ }^{11}$; Fraedrich et al. (2014) ${ }^{12}$; Furda et al. (2010) ${ }^{13}$; Guerra (2014) ${ }^{14}$; Hendrickson et al. (2014) ${ }^{15}$; Howard et al. (2014) ${ }^{16}$; Le Vine et al. (2014) ${ }^{17}$; Lutin et al. (2013) ${ }^{18}$; Shaheen et al. $(2006)^{19}$; Silberg et al. $(2012)^{20}$; Somers et al. (2015) ${ }^{21}$.

\section{3: Potential Disadvantages}

In addition to the number of potential advantages found in existing literature associated with automated vehicles, there are also a number of potential disadvantages that were identified. For example, vehicle automation is estimated to make driving easier and cheaper, which may influence an increase in automobile dominance, vehicles trips, and vehicle miles traveled (VMT), and also negatively impact other modes of transportation, like walking and biking (Guerra, 2014; Fagnant et al., 2014; Cheon, 2003; U.S. DOT, 2015; Bierstedt et al., 2014; Dutzik et al., 2013; Hendrickson et al., 2014; Anderson et al. 2014). The technology could also involve some social 
equality issues, problems with security and privacy, raise some ethical discussions, and even worsen safety on public roadways (Le Vine et al. 2014; Fagnant et al., 2014; Somers et al., 2015; Schoettle et al., 2014; Silberg et al., 2012; Anderson et al., 2014; Flämig et al., 2015).

Considering the abilities and probable accuracy of automated vehicles, lane widths, pavement designs, and rules of the road have the potential to be adjusted in order to accommodate this new technology (Somers et al., 2015; Hendrickson et al., 2014). Platooning may require special lanes and additional space for vehicles joining and separating from platoons (Lutin et al., 2013). Vehicle trips and patterns will likely change as vehicles will no longer require a driver (Fagnant et al., 2014; Silberg et al., 2012). Parents could allow their children to be driven around in a fully-automated vehicle by themselves. Additionally, fully-automated vehicles would be able to relocate themselves without any passengers. Overall, many industries, like public transportation, taxi, limousine, private auto ownership, and tracking industries, will probably shift and adapt to incorporate vehicle automation (Lutin et al., 2013). In addition to the potential for automated vehicles to change many characteristics of travel, they may also pose a risk to and impact other modes of transportation. If we assume an increase in convenience, safety, and overall enjoyability in automated vehicle travel, then walking, cycling, and public transit ridership may suffer as a result of automation (Bierstedt et al., 2014; Hendrickson et al. 2014).

Issues regarding cyber-security, ethics, and a misplaced planning emphasis are also being speculated by professionals. As vehicles become connected and more computerized, issues of security and privacy concerns arise as they become more vulnerable to viruses and cyber-attacks (Anderson et al., 2014). Automated vehicles may be used for criminal and terrorist activities, vulnerable to information abuse and hacking, plus the GPS tracking features and data sharing may raise issues related to privacy among users. Additionally, vehicles may be susceptible to technology malfunction and complete failure, which may put the passengers and other travelers at risk (Howard et al., 2014; Cheon, 2003; Flämig et al., 2015; Anderson et al., 2014; Hendrickson et al., 2014). 
Patrick Lin (2013) poses some interesting issues relating to the ethics of vehicle automation. He suggests that sometimes good judgment can compel us to act illegally and questions whether a self-driving vehicle should get to make that decision. Lin proposes an interesting scenario where an automated vehicle decides to come to a full stop when a small tree branch pokes out onto a highway with no incoming traffic, thus potentially causing a traffic jam and accident of non-automated vehicles not expecting the sudden stop. This suggests that a driver today would consciously make a decision to drive outside of the roadway lines and technically break the law in order to avoid the tree branch (Flämig et al., 2015).

Local governments will be responsible for addressing many issues that will arise within their jurisdiction, obliging to implement automated vehicle solutions, thus potentially creating a misplaced planning emphasis (Litman, 2014). This focus on automated vehicles has the potential to take time away from implementation of conventional transport projects, such as pedestrian and transit improvements, pricing reforms, and other demand management strategies. These examples, along with numerous others not discussed in this thesis, suggest there are many considerations to be discussed before automated vehicles are made available to the public.

Table 5.2 provides a list of the potential disadvantages associated with vehicle automation identified in existing literature. Sources provided below the table use superscripts to connect the source to the respective topic being discussed. 


\section{Table 5.2: List of Potential Disadvantages}

Increased automobile dominance, congestion and VMT 1, 2, 3, 4, 6, 8, 9, 16, 17

Impacted other modes of transportation 1, 2, 9, 14

Increased total cost, or proportion of income, spent on transportation ${ }^{1,5,10}$

Worsened security, safety and public health $1,3,5,6,7,9,10,11,15,16,17$

Increased total trip time $1,5,10$

Misplaced planning emphasis ${ }^{1,13}$

Social equality issues $1,6,7,11,15,16,17$

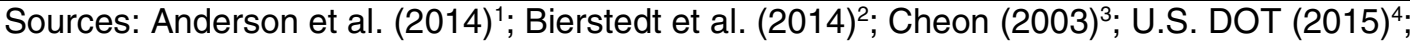

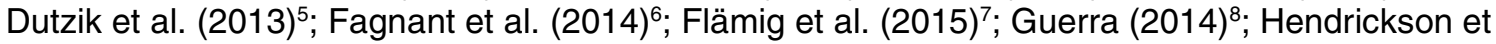
al. (2014) ${ }^{9}$; Howard et al. (2014) $)^{10}$; Le Vine et al. (2014) ${ }^{11}$; Lin (2013) ${ }^{12}$; Litman (2014) ${ }^{13}$; Lutin et al. (2013) ${ }^{14}$; Schoettle et al. $(2014)^{15}$; Silberg et al. $(2012)^{16}$; Somers et al. $(2015)^{17}$

The advantages and disadvantages discussed will not occur instantly or simultaneously as vehicle automation levels increase. The receipt of vehicle automation will depend on market adoption rates and levels of acceptance, forms of implementation, and the actual capabilities and usage of the technology. The research identified suggests that automated vehicles could improve accessibility, affordability, and comfort of travel, incentivizing more automobile usage; however, vehicle automation might also facilitate carsharing which could reduce the total number of vehicles on the roadway. Table $\mathbf{5 . 3}$ provides a comparison of the potential advantages and disadvantages discussed in this section. It is observed that there are inconsistencies in existing research; as a result, this thesis finds that the potential impacts of automated vehicles are currently not being accurately determined. 
Table 5.3: Comparison of Potential Advantages and Potential Disadvantages

\begin{tabular}{c|c}
\hline Potential Advantages & Potential Disadvantages \\
\hline $\begin{array}{c}\text { Improved safety and public health } \\
\text { Better productivity and quality of life }\end{array}$ & $\begin{array}{c}\text { Worsened security, safety and public health } \\
\text { Increased total trip time }\end{array}$ \\
$\begin{array}{c}\text { Reduced energy and environmental impact } \\
\text { Saved costs associated with roadway } \\
\text { improvements and expansions }\end{array}$ & $\begin{array}{c}\text { Increased automobile dominance, congestion } \\
\text { and VMT }\end{array}$ \\
$\begin{array}{c}\text { Decreased total cost, or proportion of income, } \\
\text { spent on transportation }\end{array}$ & $\begin{array}{c}\text { Misplaced planning emphasis } \\
\text { Increased total cost, or proportion of income, } \\
\text { spent on transportation }\end{array}$ \\
$\begin{array}{c}\text { Accommodated carsharing services } \\
\text { Increased mobility, accessibility and travel } \\
\text { options }\end{array}$ & Social equality issues \\
\hline
\end{tabular}

The contradictions identified in this thesis demonstrate an important characteristic of existing research: the industry is uncertain of the effects vehicle automation will have on congestion, automobile dominance and VMT. Based on this discovery, this thesis peruses a framework, which would attempt to answer the following questions: (1) how has society dealt with innovations in transportation throughout history; (2) how has innovation in transportation influenced travel behavior and urban growth; and, (3) are there lessons which can be used to more accurately predict how automated vehicles will influence change in congestion, automobile dominance, and VMT? This thesis identified there are lessons that can be used to answer these questions using key lessons from previous innovations in transportation throughout United States history.

\section{4: Lessons from Innovations in Transportation}

This thesis identified literature which evaluated how innovations in transportation influenced change in cities as well as the transportation systems themselves. The forms of transportation studied and compared were: walking and horse-carriage, omnibus, subway and commuter rail, streetcar, and private automobile. Four variables (speed, commuting cost, more- 
affluent residential distance from employment location, and less-affluent residential distance from employment location) were clearly identified in existing research to be influenced by advancements in transportation. Table $\mathbf{5 . 4}$ organizes the key lessons gathered from the literature into a matrix in order to provide a visual representation of change in speed, cost, and residential distance from the CBD for more and less-affluent households for each mode of transportation as they were adopted by society. Sources provided below the table use superscripts to connect the source to the respective topic being discussed. 
Table 5.4: Lessons from Innovations in Transportation Matrix

\begin{tabular}{|c|c|c|c|c|}
\hline & Speed & $\begin{array}{l}\text { Commuting } \\
\text { Cost }\end{array}$ & $\begin{array}{l}\text { More-Affluent } \\
\text { Residential } \\
\text { Distance from } \\
\text { Employment } \\
\text { Location }\end{array}$ & $\begin{array}{l}\text { Less-Affluent } \\
\text { Residential } \\
\text { Distance from } \\
\text { Employment } \\
\text { Location }\end{array}$ \\
\hline Walking/Horse Carriage & $-4,6,7$ & $-4,6,7$ & $-1,4,5,6,7$ & $-1,4,5,6,7$ \\
\hline Omnibus (1830-1850) & $+^{1,6,7}$ & $+++++^{1,5,6,7}$ & $++^{1,4,5,6,7}$ & $+^{1,4,5,6,7}$ \\
\hline Subway/Commuter Rail (1830s) & $++^{1,6,7,10}$ & $+++++^{1,5,6,7,10}$ & $+++^{1,5,6,7,10}$ & $+^{1,5,6,7,10}$ \\
\hline Streetcar (1850-1900) & $++^{1,4,6,7,10}$ & $++++^{1,4,5,6,7,10}$ & $++++^{1,5,6,7,10}$ & $++^{1,5,6,7,10}$ \\
\hline Streetcar Early Adoption & $++^{4,6,7,10}$ & $+++^{1,6,7,10}$ & $+++++^{1,4,5,6,7,10}$ & $+++1,4,6,7,10$ \\
\hline Streetcar Majority Adoption & $++^{4,6,7,10}$ & $++^{1,6,7,10}$ & $+++4,5,6,7,10$ & $++++^{4,6,7,10}$ \\
\hline Streetcar Complete Adoption & $++^{4,6,7,10}$ & $+^{1,6,7,10}$ & $++^{4,5,6,7,10}$ & $+++++^{4,6,7,10}$ \\
\hline Private Automobile (1908) & $+++1,4,5,7,10$ & $+++++^{1,3,5,7,9,10,11}$ & $+++++^{1,4,5,7,9,10,11}$ & $+^{1,4,5,7,9,10,11}$ \\
\hline Private Automobile Early Adoption (1950s) & $++++1,4,5,7,10$ & $++++1,3,5,7,9,10,11$ & $++++^{1,4,5,7,9,10,11}$ & $+^{1,4,5,7,9,10,11}$ \\
\hline Interstate Highway System (1956) & $+++++1,2,4,5,7,8,10$ & $\begin{array}{l}+++1,2,3,5,7,8,9,10 \\
11\end{array}$ & $\begin{array}{l}+++^{1,2,4,5,7,8,9,10} \\
11\end{array}$ & $+++^{1,2,4,7,8,9,10,11}$ \\
\hline Private Automobile Majority Adoption (1960s) & $+++++^{2,4,7,10}$ & $++^{1,3,5,7,9,10,11}$ & $++^{1,4,5,7,9,10,11}$ & $+++^{1,4,7,9,10,11}$ \\
\hline Private Automobile Complete Adoption (1970s-present) & $++++^{2,4,7,10}$ & $+^{1,3,5,7,9,10,11}$ & $++^{1,4,5,7,9,10,11}$ & $++++^{1,4,7,9,10,11}$ \\
\hline
\end{tabular}

\section{Automated Vehicle}

Sources: Anas (1998) $)^{1}$, Brueckner $(2008)^{2}$, Calfee $(1998)^{3}$, Gin $(1991)^{4}$, Glaeser et al $(2004)^{5}$, Frontier $(1985)^{6}$, LeRoy $(1981)^{7}$, Lichter $(1980)^{8}$, Massey $(1996)^{9}$, Mieszkowski $(1993)^{10}$, Nechyba $(2004)^{11}$ 
Urban economics is a branch of microeconomics that studies urban spatial structure, such as the location of households and jobs that often involves the use of economic tools to analyze urban areas. During the review of literature, the monocentric city model was identified to be the most influential depiction of urban form for the two decades following its creation and is relied upon in urban economics (Anas, 1998; Gin, 1991; LeRoy, 1981). The monocentric city model represents a central business district (CBD) as a circular-shaped area surrounded by manufacturing and residential regions in order to account for the spatial relationships between individuals and their places of work (Alonso et al., 1964). The model refers to how the price and demand for real estate changes as the distance from the CBD increases. Innovations in transportation have been shown to influence the model. It should be noted that changes in technology, transportation and communications has weakened the monocentric city model over time, simply because people are able now to commute further distances to their jobs, as well as the emergence of polycentric city shapes where there is no single city center (Anas, 1998; Gin, 1991).

Innovation in transportation has long been recognized as an important stimulus for societal change, with consequences for the spatial organization of society and general patterns of population redistribution (Lichter, 1980). In the 18th century, cities, like Boston and New York, were dense walking cities located around the water and their wharves. The omnibus, streetcars, subways, and commuter rails moved people to less dense neighborhoods allowing cities to expand to previously remote areas (Anas, 1998; Glaeser et al., 2004; Frontier, 1985; LeRoy, 1981; Mieszkowski, 1993). Much like today where cities are located in-line with highways, and growth was stimulated along sporadic points adjacent to railroad routes and stations.

Urbanization allowed both the rich and the poor to inhabit much larger urban areas (Gin, 1991; Glaeser et al., 2004; Frontier, 1985; Lichter, 1980). New transportation and communication technologies opened-up opportunities for more-affluent people to separate themselves physically and socially from the less-affluent. Since the rich use more housing than the poor, the poor benefit from living further away from the CBD where rent is lower. In addition, since the rich value 
their time more highly than the poor, the rich benefit from living nearer the center of the city, lowering their total commute times. According to the monocentric city model, the former effect dominates and the rich live farther from the CBD than the poor if and only if the income elasticity of housing demand exceeds the income elasticity of marginal commuting cost (LeRoy, 1981). Basically, as the cost of commuting increases with distance from the $\mathrm{CBD}$, the unit rent of housing must decrease. Higher wage workers had a competitive advantage from living farther from the city center; as a result, a faster and more expensive new transportation mode lead to a change in residential patterns where some higher wage workers lived farther from the center than lower wage workers (Gin, 1991).

It is widely recognized that the residential patterns observed after World War II resulted from the introduction of the automobile. When the car was first introduced in the 1910s, the majority of automobile ownership was concentrated among with most affluent households and it was practical for the rich to commute from cheaper suburban land that was unavailable to the poor. The residential patterns observed in the 1950 s and 1960 s could be described as highincome suburbs with low-income cities. The private automobile should be known for having two distinct effects on urban decentralization: first, studies (Alonso, 1964, Frontier, 1985, Brueckner, 2008) which focused on the causes of urban growth recognized the private automobile reduced transportation costs, resulting in an increase in possible distances between residences and job centers; second, cars eliminated the scale economies involved in older transportation systems (Glaeser et al., 2004). Ports and railway stations required massive fixed investments in infrastructure, resulting in cities being located around water ports and railroad hubs. Cars and trucks eliminated the fixed costs of rail depots and ports, replacing boats and trains, and making it possible for employment to decentralize throughout the county; however, other fixed costs emerged, such as parking lots, garages, and other uses of space.

The private automobile has had the most dramatic effect on cities. Prior transportation innovations had been important, but the car had radically reshaped cities because it almost entirely eliminated the need for walking (Glaeser et al., 2004). In the 1900 s, people walked from 
streetcar stops to their homes or jobs. Homes and businesses centered themselves around public transit stations, while general stores, schools, and restaurants where located within walking distance of homes. The streetcar, and other available forms of public transportation, made it possible to live further away from work, but people still needed to live in higher densities to be within walking distance of their daily services and needs.

American cities have long had the characteristic that the rich lived on the edges while the poor lived in the city centers; however, by the 1970s, wages had raised enough relative to the cost of an automobile to make automobile ownership economical for almost everyone (Gin, 1991). The more-affluent households lost the competitive advantage they previously had in suburban areas due to their exclusive possession of private automobiles. This led to the regentrification of the 1970s, and since then residential patterns changed as the more-affluent moved back into city centers, which displaced the poor. According to LeRoy (1981), the altered role of the private automobile as a means of commuting to work is responsible for this changing pattern.

Ultimately, when automated vehicles are first introduced, they will be too expensive for wide adoption without sufficient demand and economies of scale. This has been observed in past innovations in transportation, like the omnibus, commuter trains and electric streetcars, when they were first introduced into society. As these transportation innovations became available, they were generally only used by people who could afford to pay the high costs of travel. Over time, the technology became cheaper to produce and more affordable. For automated vehicle technology to operate it requires additional vehicle equipment, services and maintenance, and possibly additional roadway infrastructure. The light detection and ranging (LIDAR) system used in the Google car cost approximately $\$ 70,000$ (Silberg et al., 2012). As a result, automated vehicles may not be affordable to the masses at first, which present some equity issues when considering there are individuals who would likely benefit from this technology, like persons with disabilities, the elderly, and younger generations. 
It's difficult to predict the future, especially since automated vehicle technology is not widely adopted. In order to provide definition of the context under which vehicle automation will be released into society, this thesis provides information on the Millennial Generation, the largest and most diverse generation in American history (U.S. DOT, 2015; Sakaria, 2013).

\section{5: Millennials}

This thesis recognizes the importance in understanding the context of society to allow for better judgments and predictions on how vehicle automation will be most likely adopted. Understanding context can be an endless task as there are many factors to consider. In an attempt to simply this task, this thesis focuses on the unique characteristics of the Millennial Generation and how they will influence the implementation of automated vehicle technology.

Millennials, or Generation $\mathrm{Y}$, are the demographic cohort following Generation X. Although there are no precise dates, most researchers use birth years ranging from the early 1980 s to the early 2000 s to define the Millennials (U.S. DOT, 2015; Sakaria, 2013). They are the first generation to grow up with the hyper-connected world and have witnessed astounding advances in technology and computing over the past few decades, and as a result have become more efficient in many aspects of their life. In fact, there is good evidence suggesting the rate of new technology adoption has been increasing (Davidson et al., 2015). Felton (2008) shows that newer products and technologies have been adopted by consumers at a much faster rate than older ones; it is at least possible that automated vehicle technologies could follow this trend. Whether its Uber, Zipcar or Skype, Millennials are leveraging technology to discover new ways to travel or avoid traveling all together (U.S. DOT, 2015).

History has shown that the combination of technological change, such as the advent of smartphone technology, television, or radio, and forces which shape behaviors, like the Great Recession, the Great Depression, or World War II, can result in significant societal changes (Sakaria, 2013). According to Dutzik (2013), the driving boom - six decades of steady increases in per-capita driving in the United States - is over. The Millennial Generation is driving 
significantly less than previous generations of young Americans. Additionally, Millennials are the largest generation in the United States and by 2020 , nearly half (46 percent) of all U.S. workers will be Millennials (Lynch, 2008). By comparison, Generation X represents only 16 percent of today's workforce. Millennials are leading the trend of reduced driving rates and increasing alternative transportation choices.

In a study, which involved a mixture of in-depth interviews in five cities and a survey of 1000 people in six cities that are representative of the cities Millennials find attractive, Millennials were found to be more multimodal and preferred to live in cities with multiple modes of transportation (Sakaria, 2013; Dutzik et al., 2014). They are less interested in car and house ownership compared to Generation X (Dubois et al., 2011). Millennials consider public transportation as the best option for digital socializing and among the most likely to connect the user with their communities. Public transportation allows people to work as they travel, which was noted by $40 \%$ of respondents. Furthermore, $46 \%$ stating a need to save money directed their choices, $46 \%$ noting convenience, $44 \%$ want exercise, and $35 \%$ stated in their community it makes more sense to use transit. The study also stated Millennials would like to see technology leveraged to allow for real-time transit applications to "allow transit users to be more spontaneous, thus addressing the key competitive advantage of the car (Sakaria, 2013)." It's unclear if Millennials are driving less out of choice or out of economic necessity. What is clear is that Millennials are choosing how they get around, whether by carshare, bikeshare, skateboard, transit, or private vehicle, based on their budget and their lifestyle (U.S. DOT, 2015).

\section{6: Carsharing}

Carsharing is a car rental service where people rent cars for short periods of time, often by the hour. This model of service is attractive to people who make only occasional use of a vehicle as they gain the benefits of private automobile use without the costs and responsibilities of ownership (Fagnant et al., 2014). Since the mid-1980s, share-based transportation services have gained momentum (Shaheen, 2016). Carsharing has become a mainstream transportation mode for over a million users worldwide (Dowling et al., 2015). Arguably one of the more 
successful innovations in transportation, there is evidence that carsharing reduces rates of car ownership, frequency of car use and VMT (Kent et al., 2015). In the United States, carsharing services have quickly expanded, actually doubling in users every one to two years over the past decade, and have been estimated to remove approximately 9 to 13 vehicles from the road for every one vehicle made available in a carsharing fleet (Shaheen et al., 2006).

Level-5 vehicle automation has the potential to enable a new model of urban mobility by facilitating carsharing (Anderson et al., 2014; Dutzik et al., 2013; Flämig et al., 2015; Le Vine et al., 2014; Lutin et al., 2013; Somers et al.; 2015). The technology has the potential to address many barriers carsharing currently faces, like access to available carsharing vehicle locations and recirculation of vehicles. As carsharing services are able to meet the convenience levels of personal automobiles, people would likely realize the financial and spatial benefits, and move away from the traditional model of private automobile ownership. This thesis found that the combination of vehicle automation and share-based transportation services, like carsharing, has the potential to dramatically change how society moves. 


\section{CHAPTER 6: INTERVIEWS}

Based on the findings of the review of literature, this thesis developed a series of questions aimed towards learning more about vehicle automation, uncovering the inconsistencies noted in existing literature and discovering new lessons which may be underrepresented within the industry. As recommended by Patton (2015) and Murphy (1980), this thesis utilized elite interviewing techniques, and interviewed key individuals with specialized knowledge on vehicle automation, urban and transportation planning and related fields, as a way to identify and gather data. In comparison to large-scale standardized questionnaires and surveys, elite or specialized interviewing involves the collection of non-standardized information from key individuals, or thought leaders, with particular knowledge in a topic (Murphy, 1980). The interviews where unstructured in order allow for questions to be asked based on the responses from earlier questions. The experts interviewed for this thesis were: Dr. Robert L. Bertini, Dr. William Riggs, Dr. Steven Shladover, Kevin Dopart and Kenneth M. Leonard. Each interview was transcribed and attached to this document as an Appendix. The following sub-sections summarize the key findings from the interviews organized into five major themes: level-5 vehicle automation, measuring the success of automated vehicles, automobile dominance, and lessons from aviation.

\section{1: Key Findings}

- The impacts of vehicle automation differ depending on one's visions of what automation means, how it is implemented, what the automation does, and where it operates.

- Current limitations of vehicle automation to perform all aspects of the dynamic driving task in all driving conditions make it difficult to move from level-4 to level-5 automation.

- Level-5 automation is required to have any effect on carsharing, mobility, and quality of life.

- Assuming effective planning and policymaking techniques, housing preferences, urban growth, and increases in total VMT will likely not be significantly impacted by vehicle automation. 
- Human drivers may never be allowed to disengage their attention from a partially-automated vehicle, specifically in applications where drivers are expected to reengage their attention in safety-critical situations.

\section{2: Level-5 Vehicle Automation}

One of the first questions asked to every interviewee was, have you ever been skeptical of level-5, fully-automated, vehicles? While skeptical may have not been the correct descriptor, all respondents were willing to acknowledge that level-5 automation will eventually be attainable; however, they each expressed different expectations and raised a variety of questions for society to consider when developing fully-automated vehicles. In the interview, Bertini stated he's a healthy skeptic and tries to look at all sides of an issue. Bertini believes that just because we have the technology, we still have to be careful, cautious, sensible, and open about unintended consequences, and not become the victims of the technology. Bertini explained that once automated vehicles are introduced, we may find examples where people instruct their vehicle to drive around the block a few times to save on parking costs while they're inside shopping. As a society, this is not the type of behavior we want to permit. In light of this example, Bertini believes we should "not let technology drive us, [rather] let's still be focused on creating places where we want to [live] as people."

There are potentially many applications of automated technology for society to choose from; the interesting puzzle then becomes how and where automated vehicles will be deployed, and how they will influence change. During the interview, Shladover provided one of the more important and insightful findings for better understanding and anticipating the effects of how vehicle automation will impact society. Simply put, he explained that the impacts resulting from the deployment of automated vehicles differ depending on your visions of what automation might mean, how it might be implemented, what you assume the automation does, and where it operates. Shladover mentioned that you can come up with radically different answers to predicting the impacts of automated vehicles based on your vision. Professionals in research, planning, and policymaking should then start by clearly defining and understanding the 
capabilities and limitations of vehicle automation in order to better predict how society and regulators will allow automated vehicles to be implemented.

During the interview, Leonard explained that the technology is not mature enough for widespread deployment in the form of what most people think of when they think of an automated vehicle:

"[People] think of the most advanced level of automation where you open an app on your cell phone, walk out to your driveway, hop into the back of the car and it takes you to wherever you want, and you're the only person in the car. I think that's what most people think of when they think of what they want for selfdriving vehicles. That's the vision. I don't think the technology is mature enough for that to be a primary mode of transportation right now for a lot of people... I think there's a long way to go with the technology, but I think that the technology can get there."

Dr. Shladover agreed that "the leap to go from level-4 to level-5 is hugely challenging." Based on the definitions of vehicle automation, level- 5 automation would need to be achieved before the type of system being described by Leonard is possible. Shladover supported this position in the interview by explaining:

"The fundamental technology to verify and validate complicated software does not exist. There's a whole new technology that needs to be developed and matured to get to the point that somebody would have the basis of being able to say yes, indeed this system has been engineered to the level that it can indeed operate for over 3 million hours without a serious flaw."

Within the realizations discussed are hints that level-5 automation may take many years before it becomes available. In addition, Shladover raised an important point by explaining that level-5 automation is required to have any effect on the feasibility of carsharing services. The review of literature also suggests that carsharing services would likely receive an economic 
benefit from level- 5 automation due to the technological ability to automatically recirculate vehicles at potentially much lower costs. Furthermore, Millennials were shown to likely accept this form of travel due to their perceived comfort levels with leveraging technology and preferences with modes of transportation that eliminates the requirement of private vehicle ownership. This combination of a supported share-based transportation industry with a general acceptability from a majority segment of society would appear to point to all things positive for higher levels of vehicle automation; however, Shladover and Leonard explained that there are limitations that currently exist in vehicle automation making it challenging for the technology to move from level-4 to level-5 automation. As a result, the vision of a share-based, fully-automated vehicle system, where humans are never required to operate the vehicle, may not be possible for many years and is not correct at this time.

\section{3: Measuring the Success of Automated Vehicles}

Interview participants were asked how the success of automated vehicles should be measured. This question was developed based on the idea that if we understand how the success of automated vehicles should be measured, then we will be able to assign values and priorities to the potential advantages and disadvantages associated with vehicle automation. Interviewee responses discussed many different measures of success, including thoughts on safety and public health, quality of life, mobility, efficiency, congestion, time of commute or total trip time, energy and the environment, social equality, livability, and total cost of transportation for the user.

During the interview, Shladover expressed a compelling response that success must be studied as a multi-dimensional assessment, explaining that "transportation systems that are intended to maximize success along one dimension will probably not do so well along other dimensions." We could analyze vehicle automation from a safety dimension, a traffic congestion dimension, energy and environment focused dimensions, or an urban development dimension, and each dimension will pull in different directions. Looking at vehicle automation from multiple dimensions will allow transportation professionals and policy makers to better understand the 
effects of each level of automation. Similarly, each level of automation should be studied individually as the capabilities and limitations of each level vary.

Safety and public health are overwhelming concerns focused on vehicle automation as confirmed by all interviewees. Dopart made the point that we have the data available to measure changes in roadway safety since all fatal accidents are investigated. As vehicle automation increases, the 5 million crashes, 2.5 million injuries and fatality numbers per year should all decline. Similarly, Leonard agrees that if the introduction of vehicle automation results in something other than an improvement in safety, "then automated vehicles have not been implemented and deployed appropriately, or there's a problem with having a mixed fleet environment and we're having a transition problem where driver operated vehicles and selfdriving vehicles are having difficulty mixing."

In the interviews, all respondents agreed that there is surely an opportunity for automated vehicle technology to improve traffic safety. In fact, Leonard continued by stating that if we designed a system that maintains the status quo of safety, then we're missing a tremendous opportunity that technology provides and has provided historically in the past. Safety is observed to establish one threshold that must be tested and proven before vehicle automation is allowed on public roadway. Building off of the previously discussed explanations detailing the difficulty of achieving level-5 automation, Shladover, referencing a paper (Shladover, 2009) he had previously developed, put safety metrics into perspective and believes designing a system that guarantees improvements in safety is technically challenging:

"You have to start by quantifying just how safe is driving today. If we go into the U.S. traffic safety statistics and look at the frequency of fatal crashes and injury crashes, we discover that they are amazingly rare. Even though we have all the numbers... when you look at that in terms of the exposure, the fatalities occur on average once in 3.3 million hours of driving. The injury crashes once in about 65,000 hours of driving. So if you think of that in terms of mean time between failures, the designer of that system has to design a system that's going to 
operate for these tremendous amounts of hours without a fault that's serious enough to cause a significant crash. Think of those tens of thousands and millions of hours compared to mobile phones and laptop computers, and other modern software intensive devices, can you imagine what it would take to get one of these computers or one of these phones to be able to, on average across the whole population, operate for millions of hours without a dropped call or a software hiccup?"

Riggs, Bertini, and Leonard agreed that a measure of success should also be social equity. Riggs believed that fully-automated vehicles could assist in helping to bridge societal wage and societal job gaps, and generational cycles of poverty by bringing about new opportunities for people in lower and middle classes. Riggs stated, "I think there may be a crosssection of people that could potentially benefit from the increased job accessibility, and increased accessibility in general that a world of [automated] vehicles might provide." Leonard discussed how a measure of success for self-driving vehicles is the potential to help disabled veterans, survivors of accidents, or people with mobility challenges get to work or out to a function that they can't get to otherwise." Bertini agreed and encouraged the profession to think in terms of accessibility, or how accessible is a particular use or location, and if "we [are] providing equitable levels of accessibility for all our citizens." Likewise, Bertini noted measurements of success should also include total costs and the proportions of household income spent on transportation. He says that "if cost and time goes down that's probably a good thing" for society.

The opportunity for vehicle automation to improve quality of life and mobility was mentioned in some form by all interviewees. Shladover stated that automation levels would have to reach levels- 4 or -5 in order to maximize quality of life and mobility. At the highest levels of vehicle automation, people are able to use their travel time as leisure time or as work time by allowing the driver to disengage their attention from driving and apply their attention heavily on some other activity. Leonard discussed there are a whole host of things that get opened up in the mobility space, like automated van pools and mobility options improving for people who lost their 
ability to drive or never had it before. Additionally, Leonard discussed that since you don't have to drive your vehicle, you could stagger out of your house at 4 a.m., lie down in your driver's bed, press a button that says go to work, and spend the next 3 to 4 hours driving to work. Shladover and Bertini agree that's certainly a choice that some people make today.

The potential for automated vehicle technology to facilitate and encourage longer commutes may boost automobile dominance, increase VMT, and possibly cause increases in urban growth. During the interviews, questions focused on the idea of whether a significant amount of people would choose to live 3 to 4 hours away from work if vehicle automation allows them to sleep, among other things, while they are transported to their workplace. Answers reflected a general consensus that automation will likely not influence increases in total VMT and urban growth, or sprawl, within society for a variety of reasons; however, automation may contribute towards more automobile dominance. Bertini discussed that it's difficult to know what sort of value or feeling people would have about spending so much time in a vehicle:

"Some people gravitate more towards those types of long driving experiences, but it removes the human component... The idea of home is still something that people seem to value... It seems to me that people would still assign value to the interaction with the people they care about... In terms of quality of life, I think to a lot of people that means spending time and interacting with people. Even with the developments in electronics, I'm not sure that people have changed so much that they won't value human to human interactions. One of the advantages, when I think about Millennials living in the city center and maybe not wanting to own a vehicle, my sense is that part of that is they're not wasting time in commuting so they can substitute that with more fun things that they value... Overall, I still think humans are social creatures. While there may be outliers that support the 'pod-lifestyle'... most people would not."

Dopart offered an alternative perspective when he discussed how on the one hand, the suburban or ex-urban areas could end up being sprawled out, especially in areas where there is 
lower infrastructure and housing costs. In the urban areas, carsharing and new forms of Uber or Lyft style of services, could lower the cost of urban transportation and even reduce the need to own a vehicle, which has been the trend in the Millennial Generation. The potential for vehicle automation to reduce travel costs could induce more VMT. Dopart and Bertini added it comes down to simple economics of transportation:

"A shared automated vehicle could be affordable to people.... Setting aside the cost of automated vehicles right now, if you could own or subscribe to a stake in a vehicle that doesn't require a person to be paid, like a taxi, Uber, lyft model, then conceivably the cost could go down quite a bit (Bertini)."

In addition, lessons from past innovations in transportation discussed earlier in this thesis suggest level-5 automated vehicles may result in shifted housing choice preferences among more-affluent households when the technology is first released. While this opinion in based logic observed in previous trends throughout history, today's world features faster and cheaper communication channels allowing opportunities for people, like policymakers, planners and the general public, to anticipate negative behaviors and mitigate impacts. Furthermore, it is unlikely that the introduction of automated vehicles would enhance issues with congestion, urban growth and total VMT, especially considering all that society knows about these challenges today. In an interview, Riggs noted that just because you have the opportunity to choose a longer commute with the introduction of automated vehicle technology, a persons' housing choice may overshadow the distance factors:

"It relates less to the vehicle and more to what the buyer preferences are for housing. When you think about your palette of available choices for housing, [automated vehicles] have the potential to open that choice set up... It may allow some people to live further away from where they work; however, the ultimate goal is it actually opens up potentially more ease of travel opportunity for people who live more distantly irrespective of how much they make." 
Whether or not vehicle automation will encourage more vehicle dominance in society is difficult to say. In fact, Riggs added that automated vehicles may work in opposition with efforts towards getting people out of their vehicles into more active forms of transportation. Automated vehicles may encourage some people to live further away from the CBD. However, Bertini explained that it's difficult to know what sort of value or feeling people would have about spending so much time in a vehicle; people tend to value their interaction and their time with the people they care about, and would not want to spend that time in a vehicle. Society and decision makers recognize the costs associated with urban growth, automobile dominance, and increase in total VMT. From the perspective of understanding the bigger picture, automated systems that remove the act of driving will most likely not result in shifted housing preferences by the more-affluent, however, it's still a concern that should be monitored and mitigated using techniques in congestion pricing, active and non-automobile mode encouragement, and land use planning.

\section{4: Lessons from Aviation}

Shladover, Leonard, and Dopart stated there are analogous lessons in aviation and air traffic control that apply to automated vehicle technology. Shladover explained that much like the automobile, in air traffic control systems, you've got vehicles that are privately developed, owned, and operated that need to work together with the infrastructure that is publicly owned and operated. Aviation is a combination of human operation and various degrees of automation; however, Shladover clarified that today's aviation is not an automated system because we're dealing with vehicles that still have highly skilled operators sitting up front, watching over it all the time, and taking over if anything goes wrong; that is essentially an autopilot feature and would be categorized as level-2 automation.

Additional research identified the two major aircraft manufactures to have developed different philosophies regarding the authority of automation: hard automation and soft automation. Airbus uses a 'hard protection' system which acts in the form of automated interventions to prevent the pilot for inadvertently exceeding safety limits. Hard automation has ultimate authority and can override the human operator's input. On the other hand, Boeing uses a 'soft protection' 
system as a tool to aid pilots, allowing pilots full authority to override the automated system. The automatic gearbox, anti-lock brake systems, traction control, and electronic stability programs are examples of hard automation in automobiles-leaving out the option to arm or disarm the systemthat are designed to intervene purely based on vehicle dynamics. In comparison, adaptive cruise control could be classified as soft automation, since it is fully acceptable by the driver and any manual control will override the system. According to Young et al. (2007), lack of coordination has emerged as the central issue in both hard and soft automation philosophies in aviation. As a result of issues observed in aviation, the allocation of function and automated design will examine coordination and cooperation between the human driver and automation technology in automobiles (see Young at al., 2007, for a summary). There is a wealth of knowledge that exists in the aviation and automotive research domains that examine issues associated with the interaction between humans and complex systems. Due to the limitations of this thesis, these issues are discussed entirely; however, the complexity of human and automated vehicle technology interactions suggests a slower adoption of other level-2 automation applications as well as support that level-3 automated features may never be permitted.

Dopart introduced an interesting analogy discussing how cars to-date, like new Mercedes, have at least twice as many lines of code compared to the newest Boeing 787 . He continued by explaining how automobiles on the road are in a much more complex operating environment compared to what we see in aviation. "The air is pretty simple so your crash avoidance problem is much simpler," Dopart said, "you have three dimensions to move in, and you can detect things in minutes or 10 s of seconds." On roadways you're dealing with a couple of seconds to react, often a fraction of a second; this is a much more complex environment. Similarly, Shladover compared the complexity of the aviation system with the complexity of a system with level-5 automated vehicles:

"I came up with about a factor of 10 orders of magnitude greater difficulty for the road vehicle automation compared to aircraft autopilot. You think of the number of targets that each vehicle has to keep track of and you think of how 
accurately it needs to know the location and relative speed of all of those targets compared to its own location and speed. How much time does it have to make a safety critical decision when there's a problem? Think of what you can afford to spend on the system. There's a variety of factors like that, that makes [vehicle automation] much harder than doing aircraft autopilot."

During the interviews, Leonard and Dopart solidified the problem of relying on people to reengage in systems with partial automation, particularly level-3 automation. Dopart explained that the problem is you cannot depend on people to re-engage in the operation of a vehicle during emergency situations. He confirms that research has identified the average time to get someone back engaged where they could safely operate a vehicle was 7 seconds. There's also a concern that people are going to make bad decisions and use the technology, whether intentionally or unintentionally, in an irresponsible manner. Leonard explained:

"Somebody might take a level-2 technology and act as if it's a level-4 technology. That might work for a couple dozen miles, [but] then it doesn't. One of the things I worry about is making sure we are aware of the limitations of the technology as they get exposed to it... People need to understand what the technology will and will not do."

Dopart continued by explaining how there are things people do well and computers do well. One thing people don't do well, that's been observed in aviation, is remaining engaged by monitoring the system when you have an airplane that's mostly on autopilot. What's even worse is when pilots' skills deteriorate because they're flying less often. Dopart explained how the FAA basically told the airlines they're going to have to make the pilots fly more often. Dopart reassured:

"[This] is going to be a question in any automated mode... It's my opinion that the highway level-3 operations, where you could be watching a video for 10 minutes legally, but then be expected to grab the wheel in 5 seconds, [should never] be allowable." 
Dopart raised another analogous example from aviation, suggesting that someday policymakers may be considering areas where older-style vehicles are not permitted. Dopart explained, "In aviation, you cannot operate an old airplane in national airspace... you have to have newer navigation and radio equipment." Just as there are a lot of places where older planes without the latest technology can operate, there may be places in the future where antique vehicles can and cannot operate. Dopart suggested that these places will probably not be where people use vehicles the most.

Overall, there is evidence from the potential benefits of vehicle automation and lessons from aviation that suggests we may never allow partially automated (level-3) systems in private automobiles (Blanco et al., 2015). In this context, a partially automated system is where drivers are given the option to completely disengage their attention, handing all safety critical controls over to the automated system until instructed to re-engage. Aviation is a combination of human operation and various degrees of automation. Airplanes have highly skilled operators, who watch over the system and its environment at all times, and take over if anything goes wrong. As Shladover explained, this is an example of an autopilot system, not an automated system. In motor vehicle operations, vehicles often travel within a matter of seconds from each other. Dopart confirmed, the average time to get someone back engaged where they could safety operate a vehicle is 7 seconds; at highway speeds, 7 seconds is a very long time and there is a lot that can go wrong in that time. In addition, as vehicle automation progresses, Dopart suggested that vehicles without certain technologies may become banned in certain areas within a city. Discovery of these parallel lessons from aviation that could be applied to more accurately predicting the short- and long-term outcomes of vehicle automation suggests future research should analyze the implementation of automation the aviation industry in more detail. 


\section{CHAPTER 7: GOVERNMENT ROLES}

\section{1: Federal Government Role}

The United States Department of Transportation (U.S. DOT) is responsible for conducting research, assessing impacts, communicating results, coordinating with stakeholders, providing guidance, education, and assistance, encouraging appropriate standards and policies, and providing oversight and enforcement. Current research of the U.S. DOT includes aims to enable and accelerate the development and deployment of automation vehicles, while ensuring safe and efficient operations, and maximizing public benefits. The U.S. DOT's Intelligent Transportation Systems Joint Program Office (ITS JPO) is conducting an ongoing intelligent transportation program to research, develop, and operationally test intelligent transportation systems, and to provide technical assistance in the nationwide application of those systems as a component of the surface transportation network (U.S. DOT, 2015). As of late, the ITS JPO (2014) has established an automation research program within the ITS Strategic Plan 2015-2019. One of the objectives on this program is to enable safe, efficient, and equitable integration of automation into the transportation system. In addition, the Plan highlights connected vehicles as a primary focus for adoption and eventual deployment of the automated system.

NHTSA is responsible for developing, setting, and enforcing federal motor vehicle safety standards and regulations. According to NHTSA, there are three streams of innovation and technological development that are occurring simultaneously: (1) in-vehicle crash avoidance systems that provide warnings and/or limited automated control of safety functions, (2) vehicle-tovehicle (V2V) communications that support crash avoidance applications, and (3) automated vehicles. V2V and vehicle-to-infrastructure (V2I) commutations are wireless exchanges of information between vehicles, roadway infrastructure and other components of the transportation system. NHTSA finds these emerging technologies to be part of a continuum of vehicle control automation, which may offer significant crash reduction benefits. 
NHTSA (2013) has been working on level-1 automation and has begun or are planning to research level-2 through level-5 automation. The agency has identified three key areas to conduct research on advanced automated systems: human research factors, development of system performance requirements, and addressing electronic control system safety. Human factors research focuses on the goal of developing requirements for the driver-vehicle interface such that drivers can safely transition between automated and non-automated vehicle operation, as well as safely communicating relevant information to the driver. At this time, this research primarily focuses on level-2 and level-3 automated systems. System performance requirements focus on developing any potential technical requirements for automated vehicle systems. Electronic control systems safety focuses on the safety, reliability and cybersecurity of electronic control systems.

As of January 2016, NHTSA is committed to working with industry and key stakeholders over the next six months to develop guidance on the safe deployment and operation of automated vehicles. In addition, NHTSA will work with state partners to develop a model policy on automated vehicles that offers a path to consistent national policy. The following section details the most recent recommendations from NHTSA for state legislators regarding the licensing, testing, and operation of automated vehicles on public roadways.

\section{2: State, Regional, and Local Governments Role}

Manufacturers must certify that their automated vehicle technology has been successfully tested, meet certain safety requirements, and is ready for the general public to operate on public roadways through federal agencies. Once automated vehicle technologies are permitted on public roadways, state agencies will then be responsible for establishing rules and requirements for automated vehicle operations. NHTSA offers recommendations to state drafters of legislation and regulations governing licensing, testing, and operation of automated vehicles on public roadways. NHTSA believes states are well suited to address issues such as licensing, driver training, and conditions for operations of specific vehicle types. However, NHTSA recommends that states permit the operation of high-automation vehicles for testing purposes only. 
Understanding that some states are anxious for guidance with regard to automated vehicles, NHTSA offers the following recommendations:

- Ensure that the driver understands how to operate an automated vehicle safely

- Ensure that on-road testing of automated vehicles minimizes risks to other road users

- Limit testing operations to roadway, traffic and environmental conditions suitable for the capabilities of the tested automated vehicles

- Establish reporting requirements to monitor the performance of automated vehicle technology during testing

- Ensure that the process for transitioning from automated mode to driver control is safe, simple, and timely

- Automated test vehicles should have the capability of detecting, recording, and informing the driver that the system of automated technologies has malfunctioned

- Ensure that installation and operation of any automated technologies does not disable any federally required safety features or system

- Ensure that automated test vehicles record information about the status of the automated control technologies in the event of a crash or loss of vehicle control

In addition to vehicle automation, ITS JPO and NHTSA are working simultaneously on invehicle crash avoidance systems that provide warnings and/or limited automated control of safety functions, as well as V2V and V2I communications. These technological innovations are identified as an important enabler of vehicle automation and should be focused on before vehicle automation. Although V2V and V2I were not discussed thoroughly in this thesis due to the narrowed focus, it is recommended that state, regional and local government agencies realize the importance of connectivity to support vehicle automation. 


\section{CHAPTER 8: IMPLICATIONS AND CONCLUSIONS}

The objective of this thesis was to develop a strong foundation for anticipating the potential impacts resulting from advancements in vehicle automation to be used a guide for planners and policymakers. Five significant findings emerged from this thesis: (1) the impacts of vehicle automation differ depending on one's visions of what automation means, how it is implemented, what the automation does, and where it operates; (2) current limitations of vehicle automation to perform all aspects of the dynamic driving task in all driving conditions make it difficult to move from level-4 to level-5 automation; (3) level-5 automation is required to have any effect on carsharing, mobility, and quality of life; (4) assuming effective planning and policymaking techniques, housing preferences, urban growth, and increases in total VMT will likely not be significantly impacted by vehicle automation; (5) human drivers may never be allowed to disengage their attention from a partially-automated vehicle, specifically in applications where drivers are expected to reengage their attention in safety-critical situations. To guide planners and policymakers at all levels, a proposed future scenario was developed based on the findings and discussions documented throughout this thesis. The following section details a potential future scenario, which was assumed in order to recommend guiding principles for policymakers, and implications for planners, engineers, and researchers.

\section{1: Proposed Future Scenario}

This section envisions a potential future scenario of vehicle automation and related technologies assumed over the next five to ten years. From the perspective of understanding the bigger picture, the proposed future scenario recognizes a more likely implementation prediction and outcome resulting from the adoption of higher levels in vehicle automation. The future scenario was used to construct recommended guidance for policymakers, as well as implications for planners, engineers, and researchers provided in following sections.

Level-2 vehicle automations, such as autopilot features, are available as an additional or standard upgrade in higher-end vehicles. Level-2 automation technology allows the vehicle to 
automatically control lane-holding maneuvers, as well as speed control when directed by the human driver; however, human drivers are responsible for maintaining their hands on the steering wheel and full attention on the roadway as well as the automated system(s). Most new automated vehicle technologies follow the soft automation philosophy where a human driver's input will override the automated system. Applications of level-2 automations have been researched, tested, and are becoming utilized in the movement of freight and in bus transportation, primarily in the form of longitudinal cooperative adaptive cruise control used to enhance safe operations of higher-speed services. The freight industry observes many benefits from level-2 vehicle automation, primarily from saved costs and efficiencies associate with truck platooning applications, which have started to become available along major trucking routes. Drivers of these automated systems require special training.

Level-3 automation has not been authorized by federal agencies and is not permitted on public roadways in any environment. NHTSA has established that human drivers are not permitted to disengage their attention from the operation of a vehicle, except in situations where level-4 and level-5 automation is available. Human factors research, which focuses on the goal of developing requirements for the driver-vehicle interface such that drivers can safely transition between automated and non-automated vehicle operation, finds this transition to be too complicated at this time and has not approved level-3 automation. In addition, much like the research identified in this thesis, the perceived benefits of an automated system, like quality of life, mobility, accessibility and equality, are only expected to result from a fully-automated (level-5) system where drivers are never required to operate the vehicle. Based on this understanding, society, innovators, and industry leaders currently focus all of their attention on implementing applications of level-4 and level-5 automation.

Level-4 automation is the highest level of automation that has become available for use on public roadways. Transportation systems are utilizing early applications dedicated to the development of special-purpose, low-speed automation in the form of fully-automated shuttles. Companies, like Navya and EasyMile, are working with cities and counties to enhance mobility 
and accessibility in areas underserved by existing transportation systems. Early applications of fully-automated shuttles serve as first-and-last mile solutions, providing easy and convenient connection to nearby public transportation. These vehicles generally operate in controlled environments, but often mix with other users, such as pedestrians, cyclists, and bus transportation systems. Due to issues with fleet mixing and vehicle speeds, fully-automated shuttles generally to not share roadways with human-operated vehicles. In addition, level-4 technologies are observed to become feasible applications for home-delivery, yet only a few examples exist.

Level-4 vehicle automation continues to improve and society becomes more comfortable with the technology. Applications of fully-automated shuttles have begun to evolve into high speed transportation options over longer distances. Level-4 automated vehicles have been envisioned to become major facilitators in bus rapid transit (BRT) applications along routes in areas with high capacity needs. Similarly, large investments have been made in level-4 applications of U.S. freight movement to automate the transportation of goods across the country. Due to the major investments required to facilitate operations, applications of level-4 automated freight transportation have not been achieved. In addition, few examples of level-4 automation in BRT and freight movement exist due to backlash surrounding employment protection legislation.

Fully-automated vehicles are not capable of traveling on all roadway environments; therefore, level-5 vehicle automation has not been achieved. Innovation and technological development have been focusing simultaneously V2V and V2I communications as well as automated vehicles. The industry recognizes the need for public and/or private investments into $\mathrm{V} 2 \mathrm{~V}$ and $\mathrm{V} 2 \mathrm{I}$ communications to provide the required precision necessary for level-5 automated technology. Investments in V2V and V2I communications and digital mapping infrastructure have become strongly considered and have been made by leading agencies. Major gaps exist within the system which prevents fully-automated vehicles from operating in all roadway environments. Society accepts that level-5 automation is required to have any effect on carsharing, mobility, and 
quality of life. The industry is moving towards addressing the additional infrastructure and social challenges required to facilitate level-5 automated vehicles on a national level.

Looking towards the future, cities have begun discussing the feasibility of banning older vehicles without the new connected vehicle technologies, like dedicated short range communication (DSRC) systems. Larger metropolitan regions are beginning to deliberate over a potential future where human-operated vehicles are no longer permitted within higher-density areas, such as in the CBD and/or downtown. This type of closure is perceived to allow level-4 automated vehicles to circulate internally within the system, which would enhance the use of public transportation and active modes of travel. This vision is still many years from becoming realized; however, regional and local agencies have been continually looking towards connectivity, automation and other innovations in transportation to improve mobility, accessibility, and safety within their system.

\section{2: Guiding Principles for Policymakers}

As seen in many developing industries, there are people interested in pressing forward with new technologies that may, or may not, be necessarily prepared to accept the negative consequences and liabilities. Governments at all levels have a constitutional obligation to help people in the pursuit of life, liberty, and happiness, and have a responsibility to address those negative consequences by regulating products and the use of those products. In government, a policy is a deliberate system of principles used to guide decisions in order to achieve certain objectives. Policymaking is a future oriented activity that is concerned with the use of land, protection of the environment and public welfare, and is capable of confronting inconceivable problems; however, policymakers currently face their own problems by being left without a reasonable range of outcomes regarding vehicle automation. Without a fundamental understanding of how, where and when higher levels of vehicle automation will be implemented, policymakers will have a difficult time anticipating changes, and, as a result, making decisions and providing recommendations for the future. The proposed future scenario couples together the information gathered throughout the development of this thesis in order envision a "realistic" 
outcome of vehicle automation over the next five to ten years. This section provides guiding principles for policymakers based on the proposed future scenario.

As federal regulations on automated vehicle technology are established, state, regional and local government agencies should assess how implementations of automated technology will influence change over their respective jurisdictions. It is recommended that the first step in assessing these impacts should be to start a dialog in order to offer a channel of communication for the public and key stakeholders to quickly mitigate issues as they arise. Each level of government should create a task force that is responsible for organizing these discussions, educating the public and stakeholders on advancements in the vehicle automation industry, as well as vehicle connectivity technology, and providing updates on policy reforms from higher levels of government. These task forces will be responsible with conceiving and confronting the unintended consequences of vehicle automation in order to address these issues as they arise by providing corrective courses of action to mitigate impacts.

The objective of the task force program should be to enable safe, efficient, and equitable integration of automation into the transportation system. Task forces will ultimately inform and assist policymakers in developing policy. Policies established at the regional and local levels are recommended to remain flexible in order to easily adapt as new information and philosophies become available. These policies should address potential unanticipated issues with vehicle automation while not limiting potential applications and implementation strategies that are conceived as the industry and technology evolves.

Connected vehicle technology (V2V and V2I communications) should be seen as a primary focus for adoption and eventual deployment of the automated system. These technological innovations are identified as an important enabler of vehicle automation and should be focused on before vehicle automation. State, regional and local agencies shall encourage programs intended to educate staff and the public on V2V and V2I communications as well as how these systems will support applications of vehicle automation in the future. State, regional, and local agencies may begin by support for equipping traffic signals with DSRC systems that 
can communicate traffic signal phase and timing information to approaching vehicles. Installing other connected vehicle infrastructure provides more detail and accuracy of the geometry and real-time conditions of the system, which is very useful for vehicle automation.

This thesis suggests that vehicle automation technology may first become available to more-affluent households who can afford to pay the higher costs of travel. This trend has been observed in the adoptions of other transportation innovations throughout history. Regional and local agencies should support programs designed to potentially reverse this trend and encourage more equitable distribution of new transportation technologies. It is recommended that policies are developed to support equality in the system by providing economic benefits, and increased mobility and accessibility for individuals with the highest need.

This thesis assumed that effective planning and policymaking techniques will mitigate the potential for negative impacts on housing preferences, urban growth, and total VMT as a result from consumer adoptions in automated vehicles. While this may seem obvious, policymakers should remain focused on developing and reforming existing policy which reassures effective transportation and land use planning strategies. Policymakers are encouraged to continue developing policies which reduce congestion, discourage automobile dominance and excessive parking requirements, and diminish total VMT, as well as improve safety, accessibility, mobility and livability. In addition, policymakers should consider how vehicle automation could help achieve existing policy goals and objectives.

The proposed future scenario identified that potential near-term applications of vehicle automation will come in the form of first-and-last mile solutions for public transportation and freight movement. It is recommended that state, regional and local agencies provide opportunities and flexibility in their policy to allow for automated vehicle and connected vehicle applications that enable first-and-last mile and freight transportation solutions. In addition, policy should provide opportunities to leverage new innovative applications that are invented to support non-automobile travel and share-based transportation services. 
Policymakers may start considering limiting certain vehicles with, or without, certain types of technology. While this is purely speculative, more of a longer-term suggestion, and based on trends observed in aviation, human-operated vehicles may eventually become banned from accessing certain urban environments. In addition, policy may need to define specifically where vehicles equipped with certain levels of automated technology, like level-2 and level-4 automation, are allowed to operate.

There are many stakeholders that bear responsibility and have important roles in developing, implementing, and advancing automated vehicle technology. Vehicle automation has been researched for many decades, and only recently has it been progressing quickly by the industry. The industry has started taking over control and publicizing the technology, which creates a lot of interest in the public and the media. There is no doubt that we're at an exciting time in transportation, but there many articles that appear to be focused on capturing the imagination of an audience rather than presenting factual and relevant information. As a result of this realization, this thesis provides recommended implications for planners, engineers, and researchers in order to offer immediate guidance in continuing the assessment of vehicle automation.

\section{3: Conclusions for Planners, Engineers, and Researchers}

There is a big need for an education and outreach initiative to bring up people's awareness of vehicle automation. Planners, engineers, and researchers should start by remaining informed on the progression of the technology in order to accurately educate themselves and as well as the public. Newsletters and journals from respected authors and thought-leaders are recommended in order to receive accurate and the most comprehensive information. In addition, planners, engineers, and researchers should work together to encourage the public and other professionals to become more proactive and involved in vehicle automation, rather than passive recipients of technological change. It is important that with technological change, more people participate in the discussion on what they want in their communities and share their professional perspectives. Planners, engineers, and researchers should start thinking 
about how to leverage new technology in transportation to make the vehicles and users of the system more connected in order to achieve some goals, like improved mobility, efficiency and equality. It is important that technological change is not an evolution that comes from the topdown, but that communities remain focused on designing in the places where people want to live. In order to achieve this objective, one must start by being at the table, being specific about what is important, and considering what needs to change.

The review of literature of this thesis established that the impacts of automated vehicles cannot be accurately predicted at this time. During an interview, Shladover mentioned that one can come up with radically different answers to predicting the impacts of automated vehicles based on one's vision; thus, the uncertainty of automated vehicles can essentially be attributed to the uncertainty of knowing what automation means, how it might be implemented, what we assume the automation does, and where it operates. Bertini stated that in the spirit of giving people more options, there are many different ways to implement automated vehicle technology; the challenge then becomes focused around predicting what the future will look like and how will society decide to implement this technology.

In light of the information discussed throughout this thesis, the transitional periods to achieving level-5 automation are observed to create new problems that are being underaddressed in existing research. Fully-automated vehicles may be possible in the future and there are surely many benefits associate with this technology; however, the potential disadvantages of intermediate levels of autonomy introduce some complicated issues that planners, engineers, researchers, policymakers, industry-leaders, and society should be considering. Professionals in planning, engineering and research should start by clearly defining and understanding the capabilities and limitations of vehicle automation in order to better predict how society and regulators will allow automated vehicles to be implemented. Intermediate states of automation, like levels -1 and -2 , are already available on the road today; therefore, intermediate levels of automation, like level-3 and level-4 may be available on public roadways before the end state of fully-automated (level-5) vehicles. It is recommended that planners, engineers, and researchers 
focus on understanding the effects of intermediate levels of vehicle automation in the form of a multi-dimensional assessment.

Planners, engineers, and researchers should challenge themselves, as well as other community members, to think outside of the box when envisioning new strategies for implementing automated vehicles into the transportation system. One thing is clear, the next five to ten years will be extremely important in determining how vehicle automation will impact how people choose to move. Recent developments in automated vehicle technology position us on the brink of another revolution in transportation. Let's work together to encourage the public and other professionals to become more proactive and involved in vehicle automation, rather than passive recipients of technological change, so that society may benefit from applications of vehicle automation which maximize the advantages and minimize the disadvantages of this new technology. By enabling a safe, efficient, and equitable integration, automated vehicles may surely be utilized by society to achieve some goals, like improved mobility, accessibility, and safety within the system.

\section{4: Questions to Drive Future Research}

This thesis concludes by recommending questions to drive future research. The following questions are suggested questions to offer inspiration and guidance for others interested in understanding and assessing the potential impacts of vehicle automation.

- What are the potential advantages and disadvantages of automated vehicle technology and at what level of automation will they likely occur?

- What challenges need to be overcome before level-5 vehicle automation can be implemented?

- What are the benchmarks for progress in research, development and deployment of automated vehicle technology?

- What are all the potential visions one can imagine for applying different levels of automated vehicle technology? 
$\circ \quad$ How and where can each vision be implemented?

- Who benefits and who is hurt from each alternative vision?

-What are the projected timelines of each vision?

- What are the projected outcomes of each vision?

- How do we realize these visions while minimizing the potential disadvantages realized during intermediate levels of autonomy?

- What policy considerations are there to ensure housing preferences, urban growth, and total VMT are not negatively impacted as a result of vehicle automation?

- If human drivers may never be allowed to disengage their attention from a partiallyautomated vehicle, what does this mean for policy revolving the application of these types of systems?

- What are the lessons, from aviation and other evolutions in transportation, which can be used to estimate and improve the progression of vehicle automation?

\section{5: Key Takeaways}

In addition, this section summarizes the key takeaways from this thesis. The following key takeaways are provided as an effort to help bring up awareness of vehicle automation.

- The impacts of vehicle automation differ depending on one's visions of what automation means, how it is implemented, what the automation does, and where it operates.

- Level-5 automation is required to have any effect on mobility and quality of life.

- Level-5 automation has the potential to enable a new model of urban mobility by facilitating carsharing, a share-based transportation service shown to reduce the frequency of car use, car ownership, and total VMT.

- Current limitations of vehicle automation to perform all aspects of the dynamic driving task in all driving conditions make it difficult to move from level-4 to level-5 automation.

- The transitional periods to achieving level-5 automation was observed to create new problems that are under-addressed in existing research. 
- There is a big need for an education and outreach initiative to help bring up people's awareness of vehicle automation.

- Planners, engineers, and researchers should focus on understanding the effects of intermediate levels of vehicle automation in the form of a multi-dimensional assessment.

- Assuming effective planning and policymaking techniques, housing preferences, urban growth, and increases in total VMT will likely not be significantly impacted by vehicle automation.

- Human drivers may never be allowed to disengage their attention from a partially-automated vehicle, specifically in applications where drivers are expected to reengage their attention in safety-critical situations.

- Vehicle automation technology may first become available to more-affluent households who can afford to pay the higher costs of travel. This trend has been observed in past innovations in transportation, like the omnibus, commuter trains and electric streetcars, when they were first introduced into society.

- Millennials are multimodal, interested in share-based transportation services, attracted to leveraged technology for transit, and choose how they get around based on their budget and lifestyle.

- Create a task force that is responsible for organizing discussions, educating the public and stakeholders on advancements in the vehicle automation industry, as well as vehicle connectivity technology, and providing updates on policy reforms from higher levels of government.

- State, regional and local agencies should provide flexibility in their policy to allow for automated vehicle and connected vehicle applications that enable first-and-last mile solutions and freight transportation applications.

- Policy should allow opportunities to leverage new innovative applications that are invented to support non-automobile travel and share-based transportation services.

- Connected vehicle technology (V2V and V2I communications) should be seen as a primary focus for adoption and eventual deployment of the automated system. 


\section{REFERENCES}

Alonso, W. (1964). Location and land use. Toward a general theory of land rent. Cambridge, Massachusetts: Harvard University Press.

Anderson, J. M., Nidhi, K., Stanley, K. D., Sorensen, P., Samaras, C., \& Oluwatola, O. A. (2014). Autonomous vehicle technology: a guide for policymakers. Rand Corporation.

Bierstedt, J., Gooze, A., Gray, C., Peterman, J., Raykin, L., \& Walters, J. (2014). Effects of nextgeneration vehicles on travel demand and highway capacity. Fehr \& Peers Think.

Billings, C. E. (1996). Human-centered aviation automation: principles and guidelines. National Aeronautics and Space Administration (NASA).

Blanco, M., Atwood, J., Vasquez, H. M., Trimble, T. E., Fitchett, V. L., Radlbeck, J., \& Morgan, J. F. (2015). Human factors evaluation of level 2 and level 3 automated driving concepts. National Highway Traffic Safety Administration (NHTSA), No. DOT HS 812 182.

Brueckner, J. K., \& Largey, A. G. (2008). Social interaction and urban sprawl. Journal of Urban Economics, 64(1), 18-34.

Calfee, J., \& Winston, C. (1998). The value of automobile travel time: implications for congestion policy. Journal of Public Economics, 69(1), 83-102.

Cheon, S. (2003). An overview of automated highway systems (AHS) and the social and institutional challenges they face. University of California Transportation Center.

Cowen, T. (2011, May 28). Can I see your license, registration and c.p.u.?. The New York Times. Retrieved on July 152015 , from http://www.nytimes.com/2011/05/29/business/economy/29view.html?_r=2

Cyganski, R., Fradedrich, E., \& Lenz, B. (2015, January). Travel-time valuation for automated driving: A use-case-driven study. Transportation Research Board, pp. 11-15.

Davidson, P., \& Spinoulas, A. (2015, June). Autonomous vehicles: what could this mean for the future of transport?. Australian Institute of Traffic Planning and Management (AITPM) National Conference, 2015, Brisbane, Queensland, Australia.

Dizikes, P. (2010, November 5). MIT researchers test automatic parallel parking. AgeLab study: driver-assistance systems can increase wellness and safety behind the wheel.

Retrieved on June 10, 2015, from http://newsoffice.mit.edu/2010/agelab-conference-1105

Dowling, R., \& Kent, J. (2015). Practice and public-private partnerships in sustainable transport governance: The case of car sharing in Sydney, Australia. Transport Policy, 40, 58-64.

Dubois, G., Peeters, P., Ceron, J. P., \& Gössling, S. (2011). The future tourism mobility of the world population: Emission growth versus climate policy. Transportation Research Part A: Policy and Practice, 45(10), 1031-1042.

Dutzik, T., \& Baxandall, P. (2013). A new direction: our changing relationship with driving and the implications for America's future. U.S. PIRG Education Fund. Frontier Group.

Dutzik, T., Inglis, J., \& Baxandall, P. (2014). Millennials in motion: changing travel habits of young Americans and the implications for public policy. U.S. PIRG Education Fund. Frontier Group. 
Fagnant, D. J., \& Kockelman, K. (2014, January). Preparing a nation for autonomous vehicles: opportunities, barriers and policy recommendations for capitalizing on self-driven vehicles. Transportation Research Board. Washington D.C.

Fagnant, D. J., \& Kockelman, K. M. (2014). The travel and environmental implications of shared autonomous vehicles, using agent-based model scenarios. Transportation Research Part C: Emerging Technologies, 40, 1-13.

Fagnant, D. J., Kockelman, K. M., \& Bansal, P. (2015). Operations of shared autonomous vehicle Fleet for Austin, Texas, market. Transportation Research Record: Journal of the Transportation Research Board, (2536), 98-106.

Felton, N. (20008, February). How Americans spend their money. The New York Times. Retrieved on March 13, 2016 from http://www.nytimes.com/imagepages/2008/02/10/opinion/10op.graphic.ready.html

Flämig, H. (2015). Autonome fahrzeuge und autonomes fahren im bereich des gütertransportes. Autonomes Fahren (pp. 377-398). Springer Berlin Heidelberg.

Folsom, T. C. (2011, May). Social ramifications of autonomous urban land vehicles. Technology and Society (ISTAS), 2011 IEEE International Symposium on (pp. 1-6).

Fraedrich, E., \& Lenz, B. (2014). Automated driving: Individual and societal aspects. Transportation Research Record: Journal of the Transportation Research Board, (2416), 64-72.

Frontier, C. (1985). The suburbanization of the United States. New York: Oxford UP.

Furda, A., Bouraoui, L., Parent, M., \& Vlacic, L. B. (2010, May). Improving safety for driverless city vehicles: real-time communication and decision making. VTC Spring (pp. 1-5).

Gedes, N. B. (2013). Magic motorways. Read Books Ltd.

Glaeser, E. L., \& Kahn, M. E. (2004). Sprawl and urban growth. Handbook of regional and urban economics, 4, 2481-2527.

Google. (2016). Google's self-driving car project. Retrieved on February 27, 2016, from https://www.google.com/selfdrivingcar/

Guerra, E. (2015). Planning for cars that drive themselves metropolitan planning organizations, regional transportation plans, and autonomous vehicles. Journal of Planning Education and Research.

Hendrickson, C., Biehler, A., \& Mashayekh, Y. (2014). Connected and autonomous vehicles 2040 vision. No. FHWA-PA-2014-004-CMU WO 1.

Howard, D., \& Dai, D. (2014). Public perceptions of self-driving cars: The case of Berkeley, California. Transportation Research Board 93rd Annual Meeting (No. 14-4502).

Kent, J., \& Dowling, R. (2015, September). When what's mine isn't yours in collaborative consumption: the politics of parking for car sharing cars. Australian Transport Research Forum (ATRF), 37th, 2015, Sydney, New South Wales, Australia.

Kirk, B. (2016). Business opportunities in automated vehicles. Journal of Unmanned Vehicle Systems, 4, 1-3.

Le Vine, S., \& Polak, J. (2014). Automated cars: a smooth ride ahead. ITC Occasional Paper. Independent Transport Commission (ITC), No (5), 114. 
Lichter, D. T., \& Fuguitt, G. V. (1980). Demographic response to transportation innovation: the case of the interstate highway. Social Forces, 59(2), 492-512.

Lin, P. (2013, October 8). The ethics of autonomous cars. The Atlantic. Retrieved on March 21, 2015 from http://www.theatlantic.com/technology/archive/2013/10/the-ethics-ofautonomous-cars/280360/

Litman, T. (2014). Autonomous vehicle implementation predictions. Implications for transport planning. Victoria Transport Policy Institute, 28.

Lutin, J. M. et al. (2013, July). The revolutionary development of self-driving vehicles and implications for the transportation engineering profession. Institute of Transportation Engineers. ITE Journal, 83 (7), 28.

Lynch, A. (2008). ROI on generation Y employees. Bottom Line Conversations, LLC. Retrieved on March 13, 2014 from http://www.knoxvillechamber.com/pdf/workforce/ROlonGenYWhitePaper

Mack, E. (2014, October 10). Elon musk: don't fall asleep at the wheel for another 5 years. Cnet.com. Retrieved on October 15, 2014, from http://www.cnet.com/news/elon-musksees-autonomous-cars-ready-sooner-than-previously-thought/

Meyer, G., \& Beiker, S. (2016). Road Vehicle Automation 2. Springer International Publishing.

Murphy, J. T. (1980). Getting the facts: a fieldwork guide for evaluators and policy analysts. Goodyear Publishing Company. Santa Monica, CA.

National Highway Traffic Safety Administration (NHTSA). (2008). National motor vehicle crash causation survey. U.S. Department of Transportation, Report DOT HS 811059.

National Highway Traffic Safety Administration (NHTSA). (2013, May 30). Preliminary statement of policy concerning automated vehicles. Retrieved on March 3, 2015, from http://www.nhtsa.gov/staticfiles/rulemaking/pdf/Automated_Vehicles_Policy.pdf

Patton, C., Sawicki, D., \& Clark, J. (2015). Basic methods of policy analysis and planning. Routledge. New York, NY.

SAE On-Road Automated Vehicle Standards Committee. (2014, January 16). Taxonomy and definitions for terms related to on-road motor vehicle automated driving systems. Society of Automotive Engineers.

Sakaria, N., \& Stehfest, N. (2013). Millennials and mobility: understanding the millennial mindset and new opportunities for transit providers. No. Task 17, TCRP Project J-11.

Schoettle, B., \& Sivak, M. (2014). A survey of public opinion about autonomous and self-driving vehicles in the US, the UK, and Australia. Transportation Research Institute (UMTRI).

Shaheen, S. A. (2016). Shared mobility innovations and the sharing economy. Transport Policy. University of California, Berkeley.

Shaheen, S., Cohen, A., \& Roberts, J. (2006). Carsharing in North America: market growth, current developments, and future potential. Transportation Research Record: Journal of the Transportation Research Board, (1986), 116-124.

Shladover, S. E. (2009). Cooperative (rather than autonomous) vehicle-highway automation systems. 9th World Congress on Intelligent Transport Systems. 
Shladover, S. E., Lappin, J., \& Denaro, R. P. (2015). The automated vehicles symposium 2014. Road Vehicle Automation 2 (pp. 1-13). Springer International Publishing.

Silberg, G., Wallace, R., Matuszak, G., Plessers, J., Brower, C., \& Subramanian, D. (2012). Selfdriving cars: the next revolution. White paper, KPMG LLP \& Center of Automotive Research.

Somers, A., \& Weeratunga, K. (2015). Automated vehicles: are we ready? Internal report on potential implications for Main Roads WA.

Thrun, S. (2010). Research highlights toward robotic cars. Communications of the ACM, Vol. 53 No. 4, Pages 99-106. Retrieved on February 2, 2015, from http://cacm.acm.org/magazines/2010/4/81485-toward-robotic-cars/fulltext

United States (U.S.) Census Bureau. (2009-2013). Commuting characteristics by sex. American factfinder. American community survey 5-year estimates. Retrieved on July 8, 2015.

United States Department of Transportation (U.S. DOT ). (2014, December). ITS strategic plan 2015-2019. Intelligent Transportation Systems (ITS). Washington, D.C.

United States Department of Transportation (U.S. DOT ). (2016, January). Secretary Foxx unveils President Obama's FY17 budget proposal of nearly \$4 billion for automated vehicles and announces DOT initiatives to accelerate vehicle safety innovations. Briefing Room. Retrieved on March 12, 2016 from https://www.transportation.gov/briefingroom/secretary-foxx-unveils-president-obama\%E2\%80\%99s-fy17-budget-proposalnearly-4-billion

United States Department of Transportation (U.S. DOT). (2015, October). ITS joint program office. Office of the assistant secretary for research and technology. Intelligent transportation systems joint program office. Retrieved on March 12, 2016 from http://www.its.dot.gov/its_program/about_its.htm

United States Department of Transportation (U.S. DOT). (2015). Beyond traffic 2045: trends and choices. United States Department of Transportation.

United States Department of Transportation (U.S. DOT). (2015, January). Transportation accidents by mode. United States Bureau of Transportation Statistics. Reprieved on January 25, 2016.

Waldrop, M. M. (2015). Autonomous vehicles: no drivers required. National Center for Biotechnology Information. Nature, (518), 20-23.

Young, M. S., Stanton, N. A., \& Harris, D. (2007). Driving automation: learning from aviation about design philosophies. International Journal of Vehicle Design, 45(3), 323-338. 


\section{APPENDICES}

Appendix A: Interview with Dr. Robert L. Bertini

Q: Was there ever a time you were skeptical about automated vehicles?

A: I'm a healthy skeptic... I definitely try to look at all sides of an issue... It's exciting to see the increasing levels of automation in vehicles today... One subject l'm particularly interested in is: how do we deal with a mixture of vehicle types?

You have so many different jurisdictions, states and cities that have different regulations and laws. How we avoid having some sort of a patchwork, where some product will work one place and not the other...

I don't want to see us as individuals to be the victims of technology. Just because we have the technology, we have to be careful, cautious, sensible, and open about unintended consequences. In one hand, here in California and in most states, we have CO2 reduction programs, strategies, actions, that are being taken. If our big thing is to reduce VMT, on the other hand, if we're introducing automated vehicles where if you're going to the grocery store you just have your vehicle drive around the block a few times. That's not really what I think we want, but certainly it will be possible. The interesting puzzle is what the future truly will look like. In the spirit of increasing options for people, yes, all these things are options, but what do we do about the unintended consequences...How do we design communities that we want to live in? (Paraphrasing Brian Taylor of UCLA mostly in the context of congestion)... Let's not let technology drive us, let's still be focused on creating places where we want to be as people.

Q: Could automated vehicles facilitate behavior where, for example, people could live in San Luis Obispo and work in San Francisco? And, is this the type of use we want to support?

A: Original advancements in transportation were to get people out of the city. Public transportation was used to improve living conditions and increase the distance that people could live from city centers. Those were unhealthy, unsafe, places as well. The freedom to travel has 
allowed for the footprint of cities to grow. The way finance, utilities and taxation is done, you're not optimizing the shape and size of a city, but you're allowing for people to choose. So people are clearly willing, at the moment, to experience congestion and spend time traveling to and from work. In the last 20 years there has been an increasing interest in returning to the city center. It's interesting to see that public transportation is doing the opposite of what it was originally intended to do; now it's aimed to try and bring people back into the city center...

Sprawl is something that has costs associated with it, but it's not always clear how those costs are distributed. They are probably not distributed in a fair or equitable way... Allowing for more diversity in living situations, there's the shared economy concept is increasing interest. A shared automated vehicle could still be affordable to people. And actually, some of the things vehicle automation could do, setting aside the cost of automated vehicles right now, if you could own or subscribe to a stake in a vehicle, a subscription based service, that doesn't require a person to be paid, like a taxi, Uber, lyft model, a big part of that is labor. If you're taking labor out of the equation, then conceivably the cost and affordability could go down quite a bit, which could be seen as a positive.

It's hard to know what sort of value or feeling people would have about spending so much time in a vehicle, even if they [don't have] to pay attention. I still think people like the idea of home; the idea of home is still something that people seem to value. Even if you're asleep or if you're with family members who you live with, to be in a vehicle 8 hours a day, to be working 8-10-12 hours a day, and then sleeping the rest of the time. It seems to me that people would still assign value to the interaction with the people they care about. It's hard to imagine spending long periods in a vehicle as being "high quality" time (due to noise, vibration, movement limitation, etc.)

Even with the developments in electronics, I'm not sure that people have changed so much that they won't value the human to human interactions. One of the advantages, when I think about millennials living in the city center and maybe not wanting owning a vehicle, my sense is that part of that is they're not wasting time in commuting so they can substitute that with more fun things that they value. 
Some people gravitate more towards those types of long driving experiences, but it removes the human component to me if we're thinking that everyone will be living in a pod. I think it's going to take a long time before we become "pod-people." In terms of quality of life I think to a lot of people that means spending time and interacting with people. Of course, there are different ways to interact, like telecommunication, if you could reduce your commuting time by 30 minutes, you would probably fill that time with exercise, sports, or social activity. I still think humans are social creatures. While there may be outliers that support the pod lifestyle, just like we see people living in RVs, most people would not.

Q: Do you see a future where automated vehicle technology is integrated into public transportation, especially in suburb to suburb commutes?

A: I see big potential for increasing degrees of automation to be applied in fleet applications, which includes public transportation, freight, taxi, and shared services... As a fleet manager, you're looking to decrease your costs. The tradition in public transportation is that you don't want to turn it off. It still needs to operate throughout the whole day. Still needs to operate at a basic minimum headway during the off-peak, but of course it doesn't cost any less during the off-peak to provide service compared to the peak on a per-revenue mile basis. There's a huge potential because of the costs savings and safety improvements, and not to mention the big potential in innovative, flexible provision of accessibility for people who are living in suburban and urban areas. Classically public transportation has worked very well in a monocentric model, but the suburban to suburban style has not worked so well partly because of the inflexibility. Automation plus creative ways in developing services that are creating new ways of thinking about transportation in a dynamic way, no longer tied to a fixed route anymore because if you know where everyone is and where they're going you can design a service to be much more flexible.

It's hard to know exactly how it will pan out. Transit agencies are government agencies and have a specific mandate and labor rules. It will be interesting to see how these issues will be worked out. In the area of innovation, like subscription based or app based ride services, are causing cities, states, and communities to look at their traditional taxi systems that exist... Taxis exist the 
way they exist and are regulated now because they were problems in the ride provision arena where there were safety and congestion issues and cities stepped in uniformly in order to set up regulations to solve these problems. It's interesting how society is looking into the regulations that exist now and questioning if there are other ways to handle this. It's probably healthy for these growing pains and these tensions to exist and to be worked out.

Q: Do you think we should be concerned with the potential for automated vehicles to work against public transportation?

A: Definitely in the future there will be a need for high capacity, medium capacity public transportation in key corridors. In a very large city there's no physical way to move as many people as you would need to move in individual vehicles... In the future, automation could give us better space for people to live and work, relax and play, and not be so governed by parking lots and parking structures. If we're just talking about vehicle storage, there's a lot of wasted space. With automated vehicles you don't need to allow so much space for each vehicle.

Q: How should the success of automated vehicles be measured? How do we know whether it is benefiting society?

A: That's a very good question. And, who's going to be paying attention to that? If people are using products that are available, then certainly the acceptance and uptake can be measured and quantified. I think there's a movement to think about accessibility. The University of Minnesota Accessibility Observatory is trying to get people to think about how accessible a particular use or location is. Also, are we providing equitable levels of accessibility for all of our citizens? Think about how much people are paying in their total budget If their total cost of transportation (proportion of cost), if cost and time goes down that's probably a good thing. Other metrics are quality of life and livability that could also be measures of success. Safety and public health is another metric that could be measured over time.

In society, we see the pendulum swings. One generation will set up its values and character in response to the generation or generations before. On one hand, we've made a mess of things. 
Do we want to still embrace the aspects of society that lead to these environmental impacts that are pretty bad and visible. It's hard to place one generation into one bin, increasing automation will continue to be more and more available... I hope that technological advances will be used for the good. It's about creating more opportunities.

Q: How should the transportation/engineering planning professions prepare for a future with vehicle automation?

A: There's a big need for an education and outreach initiative to bring people's awareness up. I also think we should step back and look at the ingredients at what needs to change. Encourage people to be more proactive: how do you do that and spread it out through the profession? Get people talking and communicating with each other. With technological change, more people can participate in the discussion on what we want in our communities. I hope this isn't an evolution that comes from the top-down, but that communities should still focus on designing the communities they want to live in. Being at the table and being specific is important. 
Appendix B: Interview with Dr. William Riggs

Q: Do you see a future where people live multiple hours away from the workplace?

A: That's a complicated question. I think you're asking a housing choice question. It relates less to the vehicle and more to what the buyer preferences are for housing. When you think about your palette of available choices for housing, it has the potential to open that choice set up. To increase the options because you're increasing the geographic area because hypothetically you can be drowsy, you can be sleeping, hell you can be drunk in your car and you may be able to have that time in the vehicle to do other things, sleep work, etc. I think it's a provocative question whether or not people will prefer that from a location choice stand point because I think it's speculation and its relay speculative to think that people would want to reside in that context, especially in the American context where people are having a hard time getting their head around a 400 sq. foot house. I think we'd have trouble with people intellectually getting their head around actually spending that much time in such a small container. It does bring up another provocative dichotomy in that active of transportation area with a lot of emphasis on walking and biking, and it does work in opposition with the whole effort to get people active and out of their vehicles into more active forms of transit. It may allow some people to live further away from where they work. I think the ultimate goal is it actually opens up potentially more ease of travel opportunity for people who live more distantly irrespective of how much they make. As a middle class college professor who frequently takes consulting jobs in the bay area and Los Angeles, which means on a Monday or Friday if I don't have classes I may have to drive up to meet with a client. Well getting up at 3 or 4 in the morning is painful. If I could snooze in the car rather than be focused and slurping down copious amounts of coffee for 3-4 hours, let alone having to fight traffic, l'd rather work in the vehicle, catch up on email, watching a movie, even preparing for an interview, etc. that would be a benefit to me and it would be something that even as a middle class person, that would be slightly beyond my means, I would be interested in because it gives me increased economic opportunity, it gives me increased capacity to expand my reach, the amount of jobs and opportunities available to me. I think in concept, yes these things may not be available to people 
at an affordable level to start off with, but in concept it may be more egalitarian than we think now, and it may not shuffle housing the way that some people anticipate. The more I think about housing choice, housing preference, you have to separate the housing preference from the transportation choice because I think they're two different decisions. Maybe they influence one another; they're not completely linked in a way that some people are suggesting.

Q: Instead of choosing to fly from SF to LA, another option might be to hop into an automated vehicle. How will that affect the network? Will this encourage more people to use our roadways and increase congestion?

A: I think you're asking a market question. The short answer is no. If you can afford to fly to LA from SF once a week or once a month, then your time is too valuable. With the introduction of the car we saw people come out of streetcars. With the introduction of new technology, such as Uber, were seeing people becoming "taxi" drivers. You can take the perspective that this is all bad, but what it does is it suppresses prices to be more affordable. Given this, conceptually the cost of flights would go down, just like the costs of bus fairs and streetcar fairs would go down, just as the price of taxis had to adjust to the prices of Uber. Also, it reduces potential demand, so demand becomes dispersed. In every one of these cases the market achieves equilibrium. Do I think it will be this cataclysmic traffic situation, no I think the market moderates that. If traffic became so bad in certain communities, there would be revolt. It would also be an issue that if autonomous vehicles cause this big congestion problem, people would go back to flying, prices of flying would go back up. And people would say this whole autonomous vehicle thing wasn't what it was cracked out to be; it's not flushed out yet, it'll never happen, give me the wheel again. I think it more likely that, given what has happened how cars and the train poached the horse and buggy, the trains were poached by rubber tired vehicles, and those were gradually poached ultimately by widespread adoption of private automobile, I think that we will see an adjustment in the future for all of these different modes. Ultimately what I think we are gravitating towards, and will hopefully happen, is that we'll have a truly multi-modal environment where your choice set is so vast that you can optimize your travel. To choose your best mode at a certian time. That brings 
up some deficiencies, like what will be the tool to will you the best mode and will guide you in terms of your choice set to what is the optimal choice-because by and large, people are lazy and they can be predictably irrational (Dan Arielly). They can actually make irrational decisions that are not good for them based on just being presented a suite of information that is limited, and may not have considered the full amount of sunk or societal cost that one would experience. You can very easily influence behavior. So how can you actually influence people to take a trip that is most optimum for them? That is actually a provocative question and I'm not sure that is actually being done. There are a lot of companies, private and public, trying to encourage people to do what is best for the environment or what's best for the company, but maybe there is hybridization where there's some type of technological future where you can have a true understanding of what's best for the consumer in terms in time and opportunity costs.

There's also an Ayn Rand, or objectivist perspective-What's best for society as a whole is what's best for the individual. In such a situation the individual, given the right amount of information, will do for what is best for society. That's a hyper-conservative view of the world that perhaps in the past transportation planners have not accounted for, especially, environmental degradation, but I do think the pendulum has swung in the other direction where we now have a way of doing cost accounting for environmental commons type expenses. We can build those in to cost models where people can make more rational decisions based on their price of environmental damage their commute takes. For example, a cap and trade model which has been suggested for many states. If you cap the greenhouse gas emissions and you trade based on anything that exceeds it or based on the available emission. It gives you the ability to commoditize existing levels of co2 emissions. Again, the market provides a mechanism where the price is able to influence people's commute decisions.

Q: How do you think Generation $Y$ and the automated vehicle will play into the mix? (the chart) I think the scary thing is actually the population dynamic, in that Generation $\mathrm{Y}$ is comparably small compared to the baby boom generation, and I think that even though the pallet for Generation $Y$ may be this hyper-urban, affluent product, that product may not be as available as that generation 
may like. Where are they going to go when they come out of their parents basements and where are their parents going to go? They may actually find themselves more often in the suburbs. But not out of preference, out of necessity.

If and when autonomous vehicles are available to working class individuals, I would suggest they may become available in a shared environment, I think companies are already thinking about pricing structures related to shared versus non-shared structures. But if and when that becomes the case, autonomous vehicles really become a policy tool to deal with greater levels of spatial mismatch and disconnect between jobs and housing, and giving people more economic opportunity and capacity. And how much the government wants to take that on as a social program? Or just leave it to the private market in terms of who will be served? For example, certain taxi and carsharing organizations have been accused of not serving certain areas, which is the equivalent of red lining. I think that's disconcerting because there's not that level of market regulation and if we're going to see more polarization in terms of housing stock, in terms of classed based concentration in large metropolitan areas, then that's a little disconcerting. We need to think about how we stratify society a little differently.

I think the risks are mainly policy and liability related, and some of the primary safety risks are more questions about how we deal with societal overlay. And the best example I can think about is a licensing example. There are different types of driverless technology, and what you do when you end up with unskilled generation of drivers who aren't skilled at operating a manual transmission, let alone a automatic transmission. What happens when you have no other choice than having only autonomous vehicles, what do you do to regulate that? There have to be some policy decisions that have to be made to deal that level of regulation.

As a society, do we want automobiles to go away? Mothers Against Drunk Drivers can cease to exist because of autonomous vehicles. That would probably be a much better to live in, there would be much pain and less sorrow, but irrespective I think it's an important question you have to ask from a policy and ethical standpoint. 
Q: How should the success of driverless vehicles be measured over time? What are some of the variables you think should be considered? How do we know if this technology is benefiting society or helping the network?

A: All progress is good progress right? [Laugh] One has to be environmental given at where our planet is. Are there efficiencies in emissions? I think there will be. It's clear vehicles can run more efficiently, routing could be better, there's much more opportunity for shared vehicles. I think it would be almost pretty impossible to have a more inefficient system from an environmental standpoint. I would also say VMT and trip generation come to mind. Both those paradigms would change I believe. I also think that a benchmark should be social equity and do autonomous vehicles help bridge societal wage gaps, societal job gaps, and generational cycles of poverty, do they help bring about new opportunities for people that take them lower-middle class to lower class to upper class? I believe they call it the laddering approach; do they provide a ladder upward for people that are less fortunate? I do think that should be a benchmark. I'll go back to some dialogues that l've had with some Uber drivers, who are first generation immigrants, that were unable to get taxi medallions between $\$ 40 \mathrm{k}$ and $\$ 60 \mathrm{k}$, they were driving for other people, were getting back schedules, couldn't drive certain routes, had blemishes on their records and couldn't get a job. They were able to become Uber drivers, make good wages, work on their own schedule, and basically do what they wanted to do, which was drive, with a lot of ease. And that's a really interesting case study in the market responding to an ill and we've given a lot of press about inequity with regard to taxi unions, but from my experience l've met a lot of people who have done really well from an equity standpoint and are working for a company like Uber. And are the exact demographic that cannot access the taxi industry, that they're below that economic threshold, and they're hanging on for dear life, and Uber really benefits them. I think there's a cross-section of people that potentially might benefit from the job accessibility and increase accessibility that a world of autonomous vehicles might provide.

Q: How do you think society, transportation planners, or government agencies should prepare for a future with driverless vehicles? 
A: Well, obviously the first step is starting a dialog and thinking about some of these policy ramifications. I think that the policy decisions actually presuppose or should be discussed out in front of the technology primarily because they deal with their philosophical in nature, they're not technical. They're about life choices, and about people's lives, and their about value judgments. Ethical is almost a spiritual decision because they definitely bring up these values based judgments that societally we don't have. I think the region should start task forces. In California, each council of government should start a task force on this. I think that would be a start of grass roots dialog and I think the federal has already started on chatter from up high. My fear from that is that chatter will not have the same organic flavor and on the ground ethos, that will highlight these ethical issues over the technical and engineering issues. I think we can get caught up in the engineering, and miss out on the complicated and very rich policy and ethical discussions. I think that's a danger with this and I think we got to be careful that we don't get swept away by the technology and forget the personal implications.

The immediate policy discussion really cannot be flavored completely by the technical just because there are so many complex decisions that have to be made that relate back to technical, but they're nothing to do with how the onboard sensors work and how they interface with the circuitry, and how they're powered, and how quickly they can break, whether or not it's a quasiautonomous or semi-autonomous vehicle, or if the individual can react readily enough. I think that kind of stuff is so in the weeds, when do we think about the bigger policy. Are semi-autonomous vehicles worth even going after given the propensity for human error? It seems to me from a policy stand point there are only two options: fully-autonomous or driver-assist type technology; where your hands are either on the wheel, or there is no wheel. That middle ground, from a policy standpoint, informed by data, I think we want whether we want a half driving car. There is a fundamental policy decision that has to be fleshed out, and the only way that you're going to do that is starting it in two places: at the state and federal level, and the local level. Policy making sucks. It take crazy people like me that want to sit in a planning commission for 3-4 hours a night and want to make the world a better place, that are willing to slug through all the minutia of policy options to make this stuff work and kind of understand the technical but really keep your eye on 
the bigger picture. I think there a lot of people like this out there, but it's a matter of actually getting together and forming these tasks forces to make it happen. 
Appendix C: Interview with Dr. Steven Shladover

Q: Would you introduce yourself and tell me a little bit about your experience in transportation?

A: I've been working in this field for a long time. I started as a graduate student in the early 1970 s and was doing research on vehicle automation at that time. I started with degrees in mechanical engineering working on vehicle dynamics and control, but I also studied the entire civil engineering, transportation curriculum on transportation planning and modeling, combining both disciplines. I worked on a variety of topics related to this. 11 years in private industry and came to work at University of California Berkeley in 1989, and have been in UC Berkeley PATH program since then.

Q: How is California PATH facilitating the development and deployment of automated transportation systems?

A: We work in a variety of different areas. The things we work on depend on the things we're able to get research funding for. It's not just a matter of what we're interested in or what we're capable of doing, but it's also what can we find a sponsor for. Over the years we've done a great deal of work in this area. In earlier years there was substantial support from Caltrans. But Caltrans isn't nearly as active in this as they were through most of the 1990 s and early 2000 s. We have developed many automated vehicles: over 20 passenger cars, 4 transit buses, a snow-blower, and we're up to 7 heavy trucks that have been all equipped for various aspects of automated driving. We've also done a lot of modeling and simulation work to assess the transportation network, developed system architectures, and human factors experiments to understand driver reactions to different levels of automation. In current research projects, we have one working for the California Department of Motor Vehicles providing technical advice to them on the development of State regulations for automated driving. We also have a couple of projects for the Federal Highway Administration: one is developing and testing truck platooning systems using cooperative adaptive cruise control, and that involves experiments on full-scale truck; another one where we're doing traffic impacts on cooperative adaptive cruise control for passenger cars. 
We're also helping the Federal Highway Administration to develop five passenger cars with cooperative adaptive cruise control capabilities to be used as experimental test beds on a variety of tests on cooperative Adaptive Cruise Control (CACC). Those are the primary current activities.

Your visions of what automation might mean and how it might be implemented, depending on what you assume the automation does and where it operates, you can come up with radically different answers to predicting the impacts of automated vehicles.

Q: Have you ever been skeptical of a fully-autonomous, level 4 or level 5 automated vehicle?

A: I am deeply skeptical of level 5 automation. I have done a great deal of work on level 4 automation and I believe the leap to go from level 4 to level 5 is hugely challenging, and as I tell people when I speak in front of audiences, and even student audiences, don't expect to see level 5 in your lifetime.

Q: Why are you so confident with your prediction?

A: The technical challenges of making such a system no less safe than today's driving are extremely difficult. You have to start by quantifying just how safe is driving today. If we go into the US traffic safety statistics and look at the frequency of fatal crashes and injury crashes, we discover that they are amazingly rare. Even though we have all the numbers, 30,000 plus people getting killed every year, when you look at that in terms of the exposure, the fatalities that occur on average once in 3.3 million hours of driving. The injury crashes once in about 65,000 hours of driving. So if you think of that in terms of mean time between failures, the designer of that system has to design a system that's going to operate for these tremendous amounts of hours without a fault that's serious enough to cause a significant crash. Think of those 10's of thousands and millions of hours compared to mobile phones and laptop computers, and other modern software intensive devices, can you imagine what it would take to get one of these computers or one of these phones to be able to, on average across the whole population, operate for millions of hours without a dropped call or a software hiccup. That is tremendously daunting challenge, and that's why I say not in our lifetime. The fundamental technology to verify and validate complicated 
software does not exist. There's a whole new technology that needs to be developed and matured to get to the point that somebody would have the basis of being able to say yes, indeed this system has been engineered to the level that it can indeed operate for over 3 million hours without a serious flaw.

Q: Can you think of any other examples, specifically in transportation and past innovations in transportation, and what are some of those lessons learned that can be applied to autonomous vehicles?

A: I think air traffic control and automation of aircraft control is clearly an analogous example. In the air traffic control system you've got vehicles that are privately developed, owned, and operated, and you have control infrastructure that is publicly owned and operated and they need to work together. It's a safety critical system and the attempt to upgrade that in recent decades have been fraught with difficulties and indeed the system is using technology that is not very current. But the attempts to get that technology up to current levels have not been terribly successful. There are several other interesting analogies with the aircraft example. I was at a workshop a little over a year ago, in which a representative from Boeing said that when Boeing develops a new aircraft, approximately $50 \%$ of the cost of that aircraft development is software verification and validation. Another $20 \%$ is software development and the remaining $30 \%$ is everything else. Which means the airframe, the engines, the electronics, basically all the hardware on that aircraft is $30 \%$ of the development cost. So the software verification and validation is already a huge cost in that industry and we're dealing with vehicles that still have a highly skilled operator sitting up front who is watching over it all the time and is taking over if anything goes wrong. That's not an automated system. The other interesting analogy that l've used in some papers is aircraft autopilot systems, which have been in use a lot. Those are autopilots that in a sense would be level 3 automation for aircraft when they're flying up at altitude. l've compared the complexity of that type of system with the complexity of trying to do fully-automated driving, level 5 automation of road vehicles, and came up with about a factor of 10 orders of magnitude greater difficulty for the road vehicle automation compared to aircraft 
autopilot. You think of the number of target that each vehicle has to keep track of and you think of how accurately it needs to know the location and relative speed of all of those targets compared to its own location and speed. How much time does it have to make a safety critical decision when there's a problem? Think of what you can afford to spend on the system. There's a variety of factors like that, that make this much harder than doing the aircraft autopilot. That's a good example where we can learn from another transportation domain.

Q: Do you have any other reports or books on that specific topic that you would recommend?

A: There are some papers I've written on that, that I should be able to send you.

Q: How should the success of automated vehicles be measured over time? What are some of the variables that should be considered and monitored as these vehicles are introduced over time?

A: Success, that's a pretty broad category. Different people will have different priorities on what they want to accomplish in transportation and indeed systems that are intended to maximize success along one dimension will probably not do so well along other dimensions. You really have to look at that as a multi-attribute assessment. You could have a safety dimension, a traffic congestion dimension, energy and environment dimension, urban development dimension, and they're all going to pull in different directions. Maybe the simplest example is to talk about safety. Say if you really want to apply this technology of automation to maximize safety, what you would actually do is focus all your attention on level 0 and level 1 automation. You would go all out in equipping vehicles or incentivizing people to equip vehicles with collision monitoring systems and the most basic levels of driver assistance, like adaptive cruise control, or lane keeping assistance, while keeping the driver fully engaged in detecting hazards in the driving environment; therefore, you have the vigilance of the system's sensors augmenting the vigilance of the driver so if either one of them fails to detect the problem, there's a very good chance the other one will detect it. That's a way to minimize crashes and minimize crash severity. If the goal is one of the others, then it would require a very different strategy. It wouldn't be level 0 or level 1, you would have to start getting into the level 3,4 , or 5 automation. Within an energy environment, we could actually 
do pretty well with things like cooperative adaptive cruise control even at level 1 or level 2, and smoothing out traffic flow disturbances, getting vehicles operating close together in platoons, that doesn't have to get up to level 4 or level 5 automation. It will get better as it gets to level 4 , but you could still get a lot of the benefits as long as the vehicles are connected and coordinating with each other. To get to changes in quality of life, people being able to use their travel time as leisure time, or use travel time as work time, then you do have to get to level-4 or level-5 automation to allow the driver to disengage from driving and apply their attention heavily on some other activity. It's not until you get to that level that it's likely to have any effect on land use for example. Or to have any effect on feasibility on carsharing services, because for the carsharing system to be able to reposition those vehicles economically the vehicles have to be able to drive without a person on board, then we're at level 5 . Unless they're only operating in a very confined region or in special district in which case it might be level 4 . Those are going to take a long time to achieve.

Q: In an effort to prepare transportation agencies for this type of technology, is there anything that should be done at the local levels of government to prepare for this type of technology?

A: I actually think the best thing that can be done is to focus on the connected vehicle infrastructure because that will be an important enabler of the automation and that's something that's coming sooner anyway. Equipping traffic signal systems with dedicated short range communication that can communicate traffic signal phase and timing information to approaching traffic. Or putting that up on freeway entrance and exit locations, especially entrance locations that could be eventually tied into some of the ramp metering functions that could get to a point of coordinated merging points where traffic is entering the freeway. Getting that connected vehicle infrastructure in place is probably the most fruitful thing. Then there will be others associated with complicated public and private relations to deal with more detailed digital mapping of the infrastructure to provide more detail, more accurate database of the geometry and condition of the infrastructure, which can be very useful for the automation. In some cases this gets a little harder, improving the pavement markings, improving the signage, maybe getting to a point where 
the signage is more standardized than it is right now. Even though we have an MUTCD it's got an awful lot of variations and not everyone follows it. To make it simpler for the automated vehicle systems to recognized, it would surely be beneficial for infrastructure to be more consistent.

Q: Can you think of any cities or local agencies that are ahead of the game on connected vehicle infrastructure?

A: Ann Arbor had a government sponsored field test for automated vehicles. Now there are proposals pending all around the country for the next generation field test called the connected vehicle pilot development. Sometime within the next few months, the federal government will be choosing which ones they want to support and try to take that to the next stage.

Q: Are you on the board of the automated vehicle symposium?

A: I'm one of the co-chairs of that because I chair the TRB committee on vehicle highway automation. 
Appendix D: Interview with Kevin Dopart

Q: Tell me a more about yourself and how you became involved in transportation.

A: I've been involved in different aspects of transportation since undergraduate, going back when I was an aeronautical engineer and I did flight transportation grad school and flew airplanes in the Navy. After that I worked for a congressional agency that no longer exists: the office of technology of assessment. Actually some of the type of things you have here related to adoption, we actually did a project on mag-lev and aircraft as a potential for intercity transportation. There were some interesting tidbits on the introduction of technology in different parts of the world. Historically transportation and a level of communication sort of grew hand in hand because paper type of communication was tied to transportation. Those links were broken in the electronic age. Upon leaving OTA in the mid-90s the first thing I worked on was on the automated highway system federal highways program. Caltrans and UCPath were some of the members of that organization. We did the demo in San Diego in 1997 on I-15. I've still been involved in crash avoidance and pretty much worked for the ITS JPO from the contractive standpoint. Doing crash avoidance, communication and at the same time we had aviation contracts. Thanks to Google, there's been a lot more interest in automation over the last few years. JPO now has an official automation program; there was an opening and it made sense for me to come back to the feds.

Q: It seems the U.S. DOT is focusing on connected vehicle technology versus automated vehicle technology, is this correct?

A: Not quite accurate on that. I would characterize our view that the connectivity is critical to getting one of the biggest safety benefits. We don't have the hard data yet, but you really don't get mobility or environmental benefits without connectivity. You could operate autonomous vehicles that aren't connected, and the expectation is that if we get up to human quality judgement levels, given the awareness, you should have a much lower accident rate. But given your interaction with pedestrians, you're still going to be interacting with non-automated vehicles for a while. Even if they're all automated and you don't have the connectivity, you don't have to 
keep the separation distance. Only with connectivity could you bring vehicles within the .5 second or less headway separation where you can get more vehicles on the road. We're not going to be re-striping roads until we make a policy decision that old style vehicles are now prohibited, which we've done in aviation. In aviation, you cannot operate an old airplane into national airport or New York airspace; you have to have newer navigation and radio equipment. There are lots of places you can fly your old airplane and there will be places where you can drive your antique cars in the future, but they won't be in places where most people use them. With connectivity you do the platooning, close headways with aeronautic, turbulence, drag reduction to get better energy efficiency. Communication from traffic signals for doing eco-approach and eco-departure, where some of the vehicles will have optimal deceleration toward a light. Ideally the vehicle will keep enough momentum and also able to accelerate in the most efficient way possible. In this case, if all the vehicles are connected to the traffic signal, as soon as the light turns your traffic can move as a wave. As you've seen at any traffic light, it's sort of an accordion effect, where you have to wait for each car in front of you to move before you can move, because of human reaction time with everybody. With connectivity, it could be choreographed. We've done some high level modeling of urban areas looking at this. If you're in today's traffic levels, extreme cases, if all the vehicles had eco-approach and eco-departure capability, about $20 \%$ fuel efficiency over what you would normally have in city operations. That's independent of platooning, just from better operations at signalized intersections. The connectivity and the vehicles have automated longitudinal control.

Q: What is the U.S. DOT doing in terms of development and deployment vehicle transportation systems?

A: We're in a number of areas. Right now I would characterize, at least from the research program into five areas. For the most part, any of the leading edge technology tends do not to come from U.S. DOT, like anything in the artificial intelligence standpoint or advanced censors, getting LIDAR down to modular based sensors, we don't do. A few things we look at, other than developing the dedicated short range communications (DSRC), which is part of our non- 
automation safety system, but it ties to automation also. Looking at requirements for digital infrastructure. For the underling information you would need for maps at the highest level. Google has its view of something you may need. HERE, Nokia owns HERE, another mapping company. Ultimately, some states have already done or built their own LIDAR based 3D map of their federal and state highways. Utah did it I think and it wasn't that expensive. It becomes an open question of what you really need from a mapping standpoint, like connectivity it makes things better. Anything you can do with an autonomous vehicle, you can do better with connectivity. Same thing with a map; if you don't have a map, but a detailed 3D map with elevation and superelevation of the roads, all of that helps your performance. There have been studies that if you know in advance the elevation changes, you can manage your hills much better. One of the trucking companies did a study; actually some trucks are using these 3D maps to help on fuel efficiency. You don't get a big return, but even 1 or $2 \%$ is a lot of expense in the trucking industry.

Another track is what I can the safety insurance track. Really the NHTSA pre-req stuff. And some of this they have to do already for new technology, cars that are automated. Electronic systems in cars. They use to be all mechanical, now you can have breaking through a computer signal so there's not a physical connection like break by a wire or steer by a wire. How do you measure the reliability of these types of systems. NHTSA did the research, and now we're funding some add on to that research to look at it from the standpoint of these systems being used in an automated mode. When you have a driver engaged and you see a failure, its different from determining that and responding in an automated action. Electronic controls are ultimately going to decide the software. Research to date has been done in the military, NASA and aviation arena. How do you certify, assure the safety of complex software? Cars already, like top-end Mercedes, have at least twice as many lines of code compared to the newest Boeing 787. Basically, automobiles on the road are in a much more complex operating environment than aviation. The air is pretty simple, your crash avoidance problem is much simpler. You have three dimensions to move in, and you can detect things in minutes or 10 s of seconds at max. On the road your dealing if you're lucky a couple of seconds to react, often a fraction of a second. Much more complex dynamics. In the future when we're up to 100 million lines of codes, you're going to see things a lot more. By the 
time you have a real fully-automated vehicle that could operate driverless in most environments; you're working with a billion lines of code.

Q: How is the U.S. DOT planning to deal with a mixture of vehicle type on the roadways?

A: The other three tracks we're putting money in. We are developing some applications that don't have commercial market, which it tends to be the low level automation with connectivity like longitudinal cooperative adaptive cruise control. We have two truck platoon projects going on using longitudinal automation where the driver still provides the steering. We'll be testing on the road in Alabama this summer to get fuel efficiency figures. There's also another concept called speed harmonization, you would have to opt in with your car to get a signal through any communication medium, that would adjust speed on highway segments. There have been a number of studies that have tested a handful of cars with humans in the loop taking instructions, in a lot of cases you get instability in traffic because of people operating at too high of speed, and people have to decelerate and you end up with a lot of shockwaves and traffic jams. A classic example is you have the traffic jam, then it opens it up and you don't see anything. It turns out you can avoid those things by adjusting speeds by basically bringing the maximum speeds down resulting in a much better maximum through put for everybody. You only need about $4-5 \%$ participation because everybody else has to go along with people slowing down. But everybody gains. That's another project we have. We're doing a lot of lane change and merge work. Again longitudinal control, where we're working with steering but through connected communication of the vehicles you do a speed adjustment to do optimal merging or weaving. So that's the type of thing we're looking at.

We're also doing research on the NHTSA standpoint on the safety standpoint on systems that are highly automated that need a person to drive now and then or take over when the situation becomes too complex, like when suddenly there's a thunderstorm and the sensors don't work. The problem is that you cannot depend on people. If you let someone out of the loop, research to date and this has been confirmed in Europe, the average time was 7 seconds to get someone back engaged where they could safety operate a vehicle. In a car, that's a long time. For 
example, in a work zone or an incident where the police have blocked a couple lanes, that is an example where you may need to take over. That's on the borderline where you need to detect that in 7 seconds, there's also a concern that there's going to be a fraction of people that are going to fall asleep and you're not going to be able to wake them up, or they're going to do something stupid. The tests of this type of vehicle in 2017 on Gothenburg, it's on highway loop in the city. They've actually built pull-off areas. The cars are programed if the driver doesn't reengage; the car will pull into a safe harbor and stop. Because you can't just stop on the highway.

The U.S. DOT for the most part, doesn't have any authority on operations. We actually can regulate trucks and operations of trucks and transit. Now vehicle operations, that's a prevue of the states and local governments. Now that's a policy challenge coming forward because part of vehicle design in automation will be an operator, now that's a question of NHTSA's authority because NHTSA does what's called federal motor safety standards because NHTSA can regulate vehicle design and performance requirements on the design. Basically, what the person does or what the person is responsible for, is left to the states. Basically the rules of the road are a state purview also. That's why some states have different ages for drivers' licenses and different alcohol levels, etc.

Q: You've mentioned aircrafts have evolved over time, can you think of some specific lessons learned from past innovations in transportation that can be applied to autonomous vehicles?

A: Yes, some from the past and some even on-going. Certainly the question of human operated, the things people do well and computers do well. One thing people don't do well, that's happen in aviation and as well as nuclear power plant monitoring, when you have an airplane that's mostly on autopilot an you expect the pilot to be engaged when they're just monitoring, people don't do that well. FAA basically told the airlines you're going to have to make the pilots fly more often because we're seeing skill deterioration. When pilots have to re-engage they don't have the flying skills that they once had. That's going to be a question in any automated mode. If it's an operating mode where you're going to need the use the person sometimes, how do you maintain that skill? It's my opinion that the highway level 3 operations where you could be watching a video 
for 10 minutes legally, but then be expected to grab the wheel in 5 seconds, I don't think that should ever be allowable. You're going to have to have the capability of the vehicle to independently to make a safe harbor exist. Even if pulling off to the shoulder might not be good enough either, because that maybe not a good thing in most environments. If it's a highway that has rest areas, that may be acceptable.

There is also the question of cyber security. Cars for the most part are still hard to hack, there have been demos of people who have hacked into vehicles, but they had physical access to the vehicle and it took a while. The connected vehicle system, dedicated short range communication approach, is designed with security in mind, and the actually the message size is small enough that you can use formal verification methods and prevent the typical types of hacks. So we don't think that's going to be a big issues, however, cars have more and more, like Bluetooth, telematics updates, and in the future cars will have WI-FI with separate cellular connection. Also, software updates like Tesla uses. In the future everybody will be doing updates over the air, so there's a question on how that might be hacked to do an update that mandates across a bunch of cars so unsafe maneuver at a given time. The same type of thing applies to the aviation world with drones.

Q: Is the U.S. DOT concerned with the potential that automated vehicles might increase total VMT?

A: That comes down to simple economics of transportation. What happens when your cost drops? Whatever the demand curve is will probably end up consuming more of the product, which often means more trips. So we figured that will come into play. Automation and societal trends, you have two directions. In the one hand the suburban, or ex-urban, type travel, you could end up being spread especially in areas where there is lower infrastructure or housing costs. There's other infrastructure that goes into place. It comes down to who pays and who benefits. The trends in the urban areas noted in your matrix, car sharing and new forms of Uber or Lyft style of service, you're dropping the cost of urban transportation and even more so even dropping the need to even have a vehicle. That's been the trend in the millennial generation. For instance, I've 
lived in the city for a long time. I've been in D.C. since 1986, and we had one car because we have walking and bus and transit, and bike options. We had two cars for a few years while my kids were in high school, but we actually just got rid of the second car a few weeks ago and replaced it with the Car2Go option, just in case we need two cars to go somewhere. If you had a car that could be called on your phone, basically Uber without a driver will increase the convenience, which economists can measure in some form. And some of the other costs, compared to private ownership, especially in the city. The car I had was really old; I was paying as much a year for insurance as its bluebook value, so we didn't need that anymore. Cities I think are a place where different levels of automation give all types of benefits. One, where cars can pack themselves. When you do that you can fit in a whole bunch of cars in the space. One they car reposition themselves and two you don't need to open doors. So you can put them in much tighter spacing. With Uber, if the vehicle is being used $20-22$ hours a day, and if you have enough vehicles, there's probably not a lot of repositioning per-say. When they're moving they're moving with people. They just introduced the service that's trying to get away from single occupancy, where on any given trip they're going to be trying to pick up other people and guarantee that it doesn't take more than 5 minutes out of your time, but the price comes down much more. So there's an interest on a lot of those things.

Q: How should the success of autonomous vehicles be measured over time? What are some of the variables that should be considered? How would we know if this technology is improving our network?

A: The metrics that matter to the U.S. DOT directly correlate with the vehicle types. Safety for one; we have enough data, all fatal accidents are investigated; NHTSA has the FARS, which is the Federal Accident Reporting System. In the future of the type of automation on the vehicle will be accident records, so we'll have that. Certainly the mobility aspects of automation. Simply to DOT metrics of safety, different measures of mobility, total trip time. From a personal standpoint, minimizing time on your trip that you actually have to do something non-productive, like steer the car. Not quite sure how that will be tracked. If you could do it safety, that would be a measure of 
success. Fuel reduction is another. That's why the level 3 highway autopilot piece is something, other than being a precursor to enabling future applications; it doesn't do anything directly for the safety, mobility, and environmental benefits. The ability to drive your car for 10 minutes on the highway and do something else, it might be productive, and so that could be good for society. In the future we would very well want to encourage truck platooning, as long as it's safe. It's a big energy efficiency, and you get some mobility gains. Bring trucks closer together, there's some mobility aspects to that.

Q: What do you think transportation planning agencies at the local levels should be doing to prepare for automated vehicles?

A: I don't have a good answer because it's still, based on everything that we have here, difficult for vehicles to basically operate like a taxi. So we're going a reasonable speed anywhere in the city, we still see that as a decade away. Google can operate $15 \mathrm{mph}$ areas in highly mapped locations, and in most cases when there are people around, the vehicle is going to react and go very slow. The Europeans have CityMobil2, which is basically the same idea, except carry 10,12 , or 15 people. So they've done real operational testing, where they carried 10,000 people over 4 months in France without any incident. They interacted with traffic and people in a few places, but it goes quite slow. If it's clear there is nobody around, it can go up to about $13 \mathrm{mph}$. But if someone walks in front, or if you're near parked cars, it slows down. We've heard from other city folks, management type of folks have been through the DOT and ask a question: the things going to be here in 5 years we got to be ready! Probably not. But you start thinking about, would you want to have a policy at some point where all city cars have longitudinal control. From a traffic flow and energy efficiency stand point, if you can have everyone connected to signals and have the vehicles communicating to each other, there would be a lot of other efficiencies. Would you want to encourage a market of driverless vehicles? Maybe that's a good thing, but there's also the politics of dealing with the labor unions and other things, and what's that mean for transit. From the flip side of transit, how do you do evacuation? If you go to a system where you can really efficiently use fewer vehicles, Uber type driverless vehicles, they're not really great for 
evacuation. You still want busses and trains, and those are probably still the most energy efficient. You have to start thinking about how you support transit. But at the same time you can also feed more folks. We see an early application of a Google type car as a first-and-last mile solution. You're getting people to transit who had difficulty depending on the special access systems, if you could drop the costs of that and have much more frequent service, transit does become a good thing for jobs and other access. Going slow for a mile probably is not a problem if it saves you a 45 minute wait for the transit access van to come get you, for example, it could be good.

Honda as a company is looking at the city planning business and looking at what you need for transportation and how that could help as you developed for cities in the future, from the individual sized vehicles to other things. It was interesting that Honda was looking at, from a transportation standpoint, not making as many cars. They see this coming and they see bigger cities being something that's happening around the world. So there's a planned focus on mobile transportation technology. They want to be in that business, in transportation as opposed to just cars. It's about the concept of a modular city design and how you serve that with automated vehicles. 
Appendix E: Interview with Kenneth M. Leonard

Q: Would you introduce yourself and tell me a little bit about your experience in transportation?

A: I'm the Director of the Intelligent Transportation Systems Joint Program Office at US DOT. I'm an economist and program manager, who got involved working in a variety of different technology areas, and got involved in transportation in about 1991, working with the FAA. I later joined the FAA about 5 years later. Worked through a variety of positions in weather research, investment analysis, technology development, and ultimately left the FAA as the Director of Aviation Weather. I worked briefly at Federal Motor Carrier Safety Administration. For the last two and a half years l've been a director here.

Q: Tell me about the first time interested or involved in automated vehicle research.

A: Who hasn't always been interested in self-driving cars as a concept? The first time I started thinking about it was when I did a little work on technology development at FAA in the whole concept of automation, both of air traffic control and aviation vehicles. At Motor Carriers Research and Technology, I had some interest in how intelligent transportation systems were being introduced into the commercial motor vehicle space. It was pretty obvious that we were a long way off from seeing self-driving vehicles in the commercial environment. When I came to ITS Joint Program Office in December 2012, it was not really in the portfolio of the ITS Joint Program Office, which was overwhelmingly focused on connected vehicles at the time. We were in the midst of crafting our strategy, and some of the initial "getting acquainted" with the staff discussions I had here, clearly we need to introduce automated vehicles and the concept of selfdriving cars, into the research portfolio. (The response was) we work on connected vehicles here, and I said that I understand what we do on connected vehicles, but clearly there's this whole other technology area that's related but that is a more advance stage of where we are and where the technology is. I looked across the DOT portfolio, and the only real work going on in automated vehicles was in the FAA in un-manned aerial vehicles, and a little bit of truck platooning work. But that was automated functions, like automated braking. As we crafted our strategic plan from 2015 
to 2019 , I determined at that point that I wanted automated vehicles to be a part of it. We actually think that was the first year we put automated vehicles specifically into our budget at a relatively low exploratory funding level.

The other thing I would say is that it just kind of ballooned from there in terms of doing some initial exploratory work to realizing that forces were coming together, we were making enough progress on connected vehicles that we really needed to start thinking about what the US DOT role needed to be with regard to automated vehicles and bridging that gap between connected and automated vehicles. Really in that time frame we coined the phrase 'connected automation'.

Q: Would you define the role of the US DOT for connected automation?

A: I'll start with what the role of the Federal Government is not. We are not going to build automated vehicles. That is not our role. The Government has already invented a tremendous amount, and if you speak to people at Google, they will give credit to the US DOT in particular DARPA and the DARPA Challenge back in 2007. The kind of impetus and catalyst that was for advancing the whole field of self-driving vehicles. The federal government is interested in many of the fundamental research components. As I mentioned, there are things in terms of automated features and vehicle technology, like driver assist that are part of our portfolio; particularly because NHTSA (National Highway Traffic Safety Administration) has to regulate the safety of vehicles. There's an interest in some of the technology building blocks, but largely we see the technology development to be the responsibility of industry to get the technology out of the laboratory and into consumer products. It turns out that probably the biggest obstacle to getting self-driving vehicles on the road is not the technology. At this moment, I don't think the technology is mature enough for widespread deployment of what most people think of when they think of an automated vehicle. They think of the most advanced level of automation where you open an app on your cell phone, walk out to your driveway, and hop into the back of the car and it takes you to wherever you want, and you're the only person in the car. I think that's what most people think of when they think of what they want for self-driving vehicles. That's the vision. I don't think the technology in mature enough for that to be a primary mode of transportation right now for a lot of 
people. The Delphi Research had a self-driving vehicles drive across country, or about 3,400 miles, it drove $98 \%$ of the way. That leaves about 70 miles where somebody has to have their hand on the wheel. You can think about in certain environments the technology is getting great, but you would want to bet your, or someone else's life on it. I think there's a long way to go with the technology, but I think that the technology can get there. The big challenge is to move the technology to becoming widely deployed and accepted into society. The Federal Government's role is help create the environment in which the technology can be deployed to meet America's need for transportation for both people and goods can be met, and can be done in a way that the country enjoys the positive benefits without incurring the negative consequences that can come from a flawed deployment or implementation of technology.

Q: Whose responsibility would it be to look at those unintended consequences or even anticipate these issues?

A: I think there are a lot of people who have responsibility to look at that. Clearly, if you are in industry and you're going to put a product out, I think you have a reason to look at those issues. There are product liability issues associated with the products you put out, so it's important to understand the consequences of the products you put out if you're putting them out for commercial reasons. Clearly academics have an interest in assessing what's happening in society. I think you'll see that community, whether they have a responsibility to, or choose to do that because they find it a topic of interest. The media has a responsibility to keep the public informed, has a responsibility to understand what the implications of changes of society means to people. I think the government has a constitutional obligation to help people, Americans, in the pursuit of life, liberty, and happiness, have a responsibility to address those issues. In fact, governments at all levels regulate products and the use of products in ways that close the circle, that have an impact. On the consumer side, we don't just let people do whatever they want in industry because it makes a profit. You can't just dump your waste by-product into the stream and not worry about the environmental consequences and the people you killed downstream. Why would we allow someone to put a product out on the nation's streets and say you don't have to 
worry about the consequences of the people you killed down the block? Who is the one responsible entity? There is no one person in control, there is no one responsible entity. There are many stakeholders that bear responsibility and have important roles in developing, implementing, and deploying a technology. You can just look historically at what happened with transportation. 125-150 years ago, people got around by horse and carts; there were no internal combustion engines. Some of the early automobiles were steam powered, and then the internal combustion engine came along. Then in the early 1900 s more and more cars ended up on the streets, and all the sudden we had a new problem called traffic, accidents, and injuries and fatalities. Concepts that was not a common concept just a few years earlier as more and more people took to the streets in vehicles. It was less and less safe for populations to use the streets the way they had been used, which was largely by pedestrians. The streets became a place where people stopped socializing, which now happened on the sidewalks. That was a profound change that industry and government, and whole number of forces shaped. By the 1940s and 1950s the streets were largely a province for cars and not a place for people at all. Those changes happen over time and society tends to regulate them through local laws and ordinances.

There are a whole host of responsibilities that the government will have to take on in terms of automated vehicles. I think one of the big debates we're going to have to face, from a DOT perspective we look at the safety consequences from a system that kills 33,000 people a year, 5 million crashes and 2.5 million injuries. I look at automated and say there is an opportunity to change that and make it better. I think a lot of people in industry look at that and say there's an opportunity to make that better. Some of the people say in industry, and l've heard this many times, if we can just build a self-driving car that keeps things the same, we still have 5 million crashes, 2.5 million injuries, and 33,000 fatalities, that's enough. A product that maintains the status quo, but keeps people from having the inconvenience of driving, is satisfactory. I'm not sure that I share that view. I'm not sure that if we try to implement the technology in a way that said we're still going to kill 33,000 people on the nation's highways rather than require vehicle continue to improve as it has for the last 50-60 years, that we're going to accept a leveling off of 
that, then we're missing a tremendous opportunity here that technology provides and has provided historically in the past.

Q: Have you ever been skeptical of automated vehicles?

A: I'm not sure I would use the word skeptical. I've worked in advanced technology long enough to understand that some problems are difficult to solve. Edison once said, "First I learned 1,000 ways not to make a light bulb." I think we're still on the 1,000 ways to make self-driving vehicles because I don't think the vision I mentioned earlier is correct at this time. I'm not skeptical that technology is achievable. Some people think it's achievable faster, some people might think it's achievable slower. I think that largely depends on the pace of technology development in industry and how they build the market case for providing products. I think long before we see the end state automated vehicles, we will also see intermediate state levels of automation on the road. We already see intermediate states of automation on the road today. I wouldn't say that I'm skeptical of connected automated, but I recognize that some people will think it's ready before it is. And there will be people interested in pressing forward with the technology, getting deployment, but not necessarily prepared to accept the negative consequence and liabilities that come with that. We need to make sure the technology gets put out in a way that's socially responsible and keep people accountable.

Q: What are some of the lessons learned in innovations in transportation that could apply to automated vehicles?

A: There are just some fundamentals of human nature. People will do some very stupid things while driving. Somebody might take a level 2 technology and act as if it's a level 4 technology. That might work for a couple dozen miles, and then it doesn't. One of the things I worry about is making sure we are aware of the limitations of the technology as they get exposed to it. One of the examples I think about, when some of the parking assist technologies came out with backup cameras and the wheel would automatically turn; people didn't realize that they still had to press on the brake as the car backed into the spot. So people were tearing off the bumpers of the cars 
behind them and their own bumpers because they didn't realize it was parking assist and not selfparallel parking. People need to understand what the technology will and will not do. There is a strong potential to be trading off operator error with programmer error. There are a lot of situations that the programmers have to anticipate and teach the machine, or program the machine, to handle. I don't think we're far along with artificial intelligence and robotics, and certainly I don't think we have machines that can make the moral choices that operators make. For example, do I turn my car to the left knowing that l'm going to rip the side off the vehicle, but I'm going to avoid the baby carriage and the mother walking across the street? People can make that choice. It takes complex programming to get a machine to make those choices. I think there are a lot of things we're going to have to work out.

I look at the example of interoperable tolling in this country, which is something we don't have because it popped up state by state. While you may be able to take the Delphi self-driving car across country, you will need several different toll passes in your car to make sure you don't get a ticket. Some of the national interoperability issues because of the nature of how we manage the surface transportation is very different from how we manage air transportation. In air transportation we truly have a federal system with federal licensing, you're dealing with FAA at both ends of the trip in the US. As you drive across America, you're dealing with different state DMV's and DOT's. Overall, there are a whole host of things that we can learn from.

\section{Q: How could aviation be analogous to self-driving vehicles?}

A: Clearly the FAA has had autopilots for a very long time. That has been a common feature of aircraft where you could put the aircraft in what's called "in trim", and it'll fly itself for a very long time, sometimes until it runs out of fuel, or until it can't fly anymore. But you have a very different environment where aircrafts are separated by miles, and you have what they call "big sky". You don't have to stay between the lanes. There have been a number of incidents where pilots have died in flight and controllers haven't been able to contact the self-driving plane, and the plane would then be escorted by fighter aircraft until they crashed. I remember there was a famous case of a golfer a few years back, his name was Payne Stewart, whose aircraft experienced a 
decompression and just flew on from the southern part of the US up to the Dakotas until it ran out of fuel. One of the lessons are things will go wrong; you have to have redundant systems. I look into aviation and what we've designed into aircraft and think how remarkable it is given how many millions miles people fly and how many aircraft we have in flight. You can have aircraft take off from a New York airport, suck in a bunch of geese into the engine and become no longer flyable, and have an experienced captain put the plane down on a river, and have everyone get off the aircraft without a single fatality or significant injury. It has taken 100 years to get aviation to the level of safety that we have with professional crews, professional controls, flight attendants who are monitoring and supporting safety throughout the process. It's a very different process from what we have on the ground. I think we need to make sure that when we engineer transformation in the surface transportation system that we strive for a high level of safety. We've talked about working towards zero deaths. If we had not been working towards that over the last 50-60 years through improved highway safety, through changes to vehicle safety that NHTSA has required and auto manufacturers build into their vehicles now, we would be killing 130,000 people per year on our highways. If we had the fatality rate we had given the number of miles we drive, socially we wouldn't be able to tolerate the carnage on the roads. I think we have the opportunity here to cut those numbers even further through automated and connected vehicles that are going to be two big technology transformations that are going to keep bringing that number down.

Q: How should the success of automated vehicles be measured over time?

A: Clearly safety is an overwhelming focus of the department of transportation. We hope to see 5 million crashes decline, we hope to see those 2.5 million injuries to decline, and we hope to see those fatality numbers decline. That would be the measure we would be looking at. If we see an introduction of automated vehicles, and those entire things climb, then automated vehicles have not been implemented and deployed appropriately, or there's a problem with having a mixed fleet environment and we're have transition problems where driver operated vehicles and self-driving vehicles are having difficulty mixing. Now get into the mobility question, what do we want to see there? If we get tremendous safety numbers but it takes you twice as long to take a self-driving 
car, are you happy about that? Do you appreciate the time in your car and using it for something else, like entertainment, communication, sleep, reading, whatever it is that makes you willing to spend an hour and a half in the car instead of 45 minutes, if the self-driving vehicle can't get you there quickly. I think one of the things we'll look at is congestion and time of commute, especially time of commute from the same location. Another metric we're going to have to look at is well now all of a sudden when you don't have to drive your vehicle, do you could stagger out of your house at 4am, lie down in your driver's bed, press a button that says go to work, and spend the next 3-4 hours driving to work. Now you're spending 3-4 hours driving to work, we're going to have to look at some of the consequences there. Certainly that's a choice that some people make today. I think one of the things we'd be looking at is the impact on congestion and mobility. Can you do the same trip in the same amount of time? Also, have we given mobility to people who never had it before? To the senior citizen who stopped going to the library because someone stopped driving them and they either decided they're not a safe driver or the state decided they're not a safe driver and didn't renew their driver's license, are they gaining mobility? Disabled veterans, survivors of accidents who have mobility challenges, if self-driving vehicles can help those people get to work, or out to a function that they can't get to otherwise, that's a measure of success. Are you increasing mobility for people who didn't have it before? And are you increasing mobility choice for people who have very limited options? If there was one bus in the morning and one bus out in the evening they could now, but now there are other options like automated van pools or self-driving vehicles, or other things. There are a whole host of things that get opened up in the mobility space that we'll have to think long and hard of the right metrics and how do we measure them.

Finally, another area would be efficiency. We tend to think of this as fuel burn, greenhouse gasses, or other component measures. I get off of the transit station, about 2/3 mile from my house, walk to the grocery store on the way home, plus I get some exercise, not a bad commute. But if I were in a self-driving vehicle and still needed to stop at the grocery store, I might hop out of the vehicle and tell the vehicle to circle the block for three minutes. There might be 150 people getting home at the same time with the same idea, and now we have 150 empty vehicles circling 
the block. We could increase unnecessary fuel burn since we would have just parked our (nonautomated) vehicle. I think there are some metrics we're going to have to watch there to make sure we don't trade off efficiency and actually create a less efficient system. Again, if those problems happen and they're a problem for communities, communities and governments have ways to deal with them. You think about self-driving vehicles and the implications on parking. Who pays for the ticket when a car parks in a spot that is a 15 minutes parking spot, but you're not the owner of the car, you're just the person who called that car. Or maybe you are the owner of the car, but somehow the car didn't read that was a 15 minute spot. Who pays that ticket; the car manufacturer or you? Do you even need timed parking spaces? There becomes a whole host of issues that have to be resolved through the introduction of technology.

\section{Q: Do you have any good books or report which you recommend?}

\section{A: Peter Norton's historical book on transportation "fighting traffic"}

Big changes in automated technology are going to drive big changes in economics, laws, liability, privacy, cyber security. It's a much bigger picture than can I build a car that can park itself. Those things tend to have profound economic implications. One of my contentions in my career in transportation has been that what we're always trying to do with technology is increase productivity. All societal gain tends to revolve around productivity gains. 300 years ago we wouldn't be having this conversation because we'd be busy chopping down wood to build long cabins and growing enough food to sustain ourselves through winter. There were very few lawyers, doctors, writers; now $1 \%$ of the US population can feed the world through highly productive technology. We're looking for the same type of economic transformation through transportation productivity change. I believe that automated vehicles have a lot of that potential. I think connected vehicles and automated vehicles are a big part of it. I think there are going to be profound economic implications with automated vehicles.

You can think about a number of industries that revolve around the transportation system. If we're focused on instead of moving from a transportation culture of crash survivability to crash 
avoidance, you don't need to repair those cars anymore. And you don't need 2,000 pounds around you to protect you. A vehicle could be a cardboard box and it could look like the Google koala. Status symbols and other things like that change in society. If you don't need to park your vehicle downtown, all you need to know is you want it there in 10 minutes and you can press an app on your phone to order your vehicle. You don't care if it came from a parking garage on the outskirts of town that was not using valuable real-estate in the city. I think you're going to see all these things ripple through. Instead of automobile repair you'll see computer programming, or robotics repair industries are going to be growing. 
Appendix F: Biography

Charlie Coles first became interested in transportation planning and engineering while studying abroad in Copenhagen, Denmark. Time and time again, he found himself thinking, writing, and attempting to understand the differences in transportation design compared to that in the United States. Everything from the fully separated bike paths, public transit availability, and traffic signal design fully encompassed his interest. Charlie didn't realize it, but at that moment he decided to become a city and regional planner and transportation engineer in order to contribute towards designing meaningful solutions to various problems.

As his professional career in transportation progresses, Charlie reminds himself that people have an inherent urge to move and travel in order to see, smell, taste, hear and touch the world around them. The way societies move will always impact their everyday experiences, thus influencing peoples' behaviors and emotions. He believes that if transportation systems are designed correctly, they can help improve the quality of everyday life. There are many challenges with today's transportation system that he anticipates will evolve throughout his career. Overall, he hopes that his work may help to support forms of mobility that create friendlier, more sustainable, efficient, and healthier places for people to enjoy. 